\title{
Gold(II) Porphyrins in Photoinduced Electron Transfer Reactions
}

\author{
Sebastian Preiß[a], Ayla Päpcke ${ }^{[b]}$, Lukas Burkhardt[c], Luca Großmann ${ }^{[d]}$, Stefan Lochbrunner ${ }^{[b]}$, Matthias Bauer[c], \\ Till Opatz ${ }^{[\mathrm{d}]}$, and Katja Heinze[a]*
}

\begin{abstract}
In the context of solar to chemical energy conversion inspired by natural photosynthesis, we present the synthesis, electrochemical properties and photoinduced electron transfer processes of three novel zinc(II)-gold(III) bis(porphyrin) dyads [Zn" $(\mathrm{P})$-Au $\left.{ }^{\prime \prime \prime}(\mathrm{P})\right]^{+}$. Time-resolved spectroscopic studies indicate ultrafast dynamics $\left(k_{\mathrm{ET} 1}>10^{10} \mathrm{~s}^{-1}\right)$ after visible light excitation finally yielding a charge-shifted state $\left[\mathrm{Zn}^{\prime \prime}\left(\mathrm{P}^{\bullet+}\right)\right.$ $\left.\mathrm{Au}^{\prime \prime}(\mathrm{P})\right]^{+}$featuring a gold(II) centre. The lifetime of this excited state is quite long thanks to a comparably slow charge recombination $\left(k_{\mathrm{BET} 2} \approx\right.$ $\left.3 \times 10^{8} \mathrm{~s}^{-1}\right)$. The $\left[\mathrm{Zn}^{\prime \prime}\left(\mathrm{P}^{\bullet+}\right)-\mathrm{Au} \mathrm{u}^{\prime \prime}(\mathrm{P})\right]^{+}$charge-shifted state is reductively quenched by amines in bimolecular reactions yielding the neutral zinc(II)gold(II) bis(porphyrin) Zn"(P)-Aul(P). The electronic nature of this key gold(II) intermediate, prepared by chemical or photochemical reduction, is elucidated by UV/Vis, X-band EPR, gold $\mathrm{L}_{3}$-edge XANES and paramagnetic ${ }^{1} \mathrm{H}$ NMR spectroscopy as well as by quantum chemical calculations. Finally, the gold(II) site in $\mathrm{Zn}^{\prime \prime}(\mathrm{P})-\mathrm{Au}^{\prime \prime}(\mathrm{P})$ is thermodynamically and kinetically competent to reduce an aryl azide to the corresponding amine paving the way to catalytic applications of gold(III) porphyrins in photoredox catalysis involving the gold(III/II) redox couple.
\end{abstract}

\section{Introduction}

Photoinduced electron transfer (PET) can be considered as the most important chemical reaction with enormous relevance to life. ${ }^{[1]}$ It constitutes the fundamental step in natural photosynthesis as well as in many artificial devices to convert solar energy into chemical energy. ${ }^{[2]}$ Significant advances in the understanding of photoinduced charge separation have been obtained via examination of artificial reaction centres consisting of covalently linked donor and acceptor molecular units. ${ }^{[3]}$ Ferrocene ${ }^{[4]}$, carotenoid polyenes ${ }^{[5]}$ and zinc(II) porphyrins ${ }^{[6]}$ represent typical electron donor entities whereas quinones ${ }^{[4 \mathrm{c}, 4 \mathrm{~h}]}$ (natural acceptors) or fullerenes ${ }^{[4 a, 4 b, 4 d, 4 e, 4 f]}$ act as electron acceptors. Cobaltocenium ions $^{[7]}$ or gold(III) porphyrins ${ }^{[8,9,10]}$ (Scheme 1a) constitute a class of cationic electron acceptors.

Pioneering studies by Sauvage ${ }^{[8]}$, and more recently by the groups of Crossley/Fukuzumi/Kadish ${ }^{[9]}$ and Hammarström/Odobel[10] have shown that efficient and even ultrafast electron transfer $\left(k_{\mathrm{ET}}=10^{12} \mathrm{~s}^{-1}\right)$ occurs in porphyrin arrays composed of zinc(II) porphyrin chromophores and gold(III) porphyrins along with a rather low back-electron transfer rate $\left(k_{\mathrm{BET}}\right.$ $=10^{9} \mathrm{~s}^{-1}$ ) resulting in comparably long-lived charge-shifted states. ${ }^{[10 \mathrm{~d}]}$

[a] S. Preiß, Prof. Dr. K. Heinze

Institute of Inorganic Chemistry and Analytical Chemistry

Johannes Gutenberg University of Mainz

Duesbergweg 10-14, 55128 Mainz, Germany

E-mail: katja.heinze@uni-mainz.de

[b] A. Päpcke, Prof. Dr. S. Lochbrunner

Institute of Physics and Department of Life, Light, and Matter,

University of Rostock, 18051 Rostock, Germany

[c] L. Burkhardt, M. Bauer,

Department Chemie and Center for Sustainable Systems Design (CSSD), University of Paderborn, Warburger Straße 100, D-33098 Paderborn, Germany

[d] L. Großmann, T. Opatz

Institute of Organic Chemistry, Johannes Gutenberg University of Mainz, Duesbergweg 10-14, 55128 Mainz, Germany

Supporting information for this article is given via a link at the end of the document.

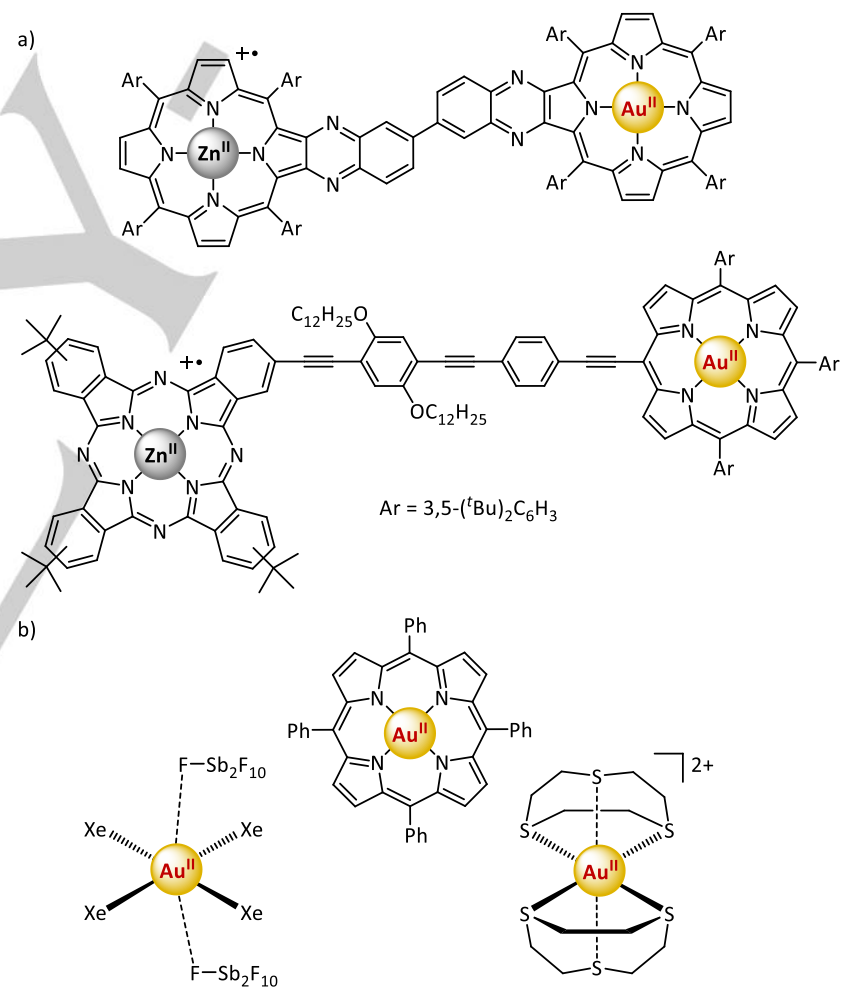

Scheme 1. a) Suggested transient charge-shifted states in zinc-gold dyads including gold(II) ${ }^{9 e, 10 d}$ and b) selection of structurally characterised genuine mononuclear gold(II) complexes. ${ }^{11,12,13}$

The high forward rate is due to $\pi$-conjugated bridges between the chromophor and the electron acceptor facilitating the electron transfer. ${ }^{[12]}$ The recombination reaction has a large driving force and hence the back-electron transfer occurs in the Marcus inverted region. Furthermore, the slow recombination has been attributed to the trapping of the electron on the gold centre retarding the back electron transfer ${ }^{[12]}$ 
The localisation of the unpaired electron at the gold centre has been unambiguously demonstrated for the paramagnetic prototype $d^{9}$ complex $A u^{\prime \prime}(T P P) \quad\left(\mathrm{H}_{2}\right.$ TPP $=$ mesotetraphenylporphyrin) by EPR and XANES spectroscopy as well as by single crystal X-ray diffraction. ${ }^{[13]}$ Apart from gold(II) porphyrins $A u^{\prime \prime}(P)$, further genuine mononuclear gold(II) complexes with $\mathrm{d}^{9}$ electron configuration are still quite rare species (Scheme 1b) due to the favoured disproportionation or dimerisation. ${ }^{[11,13 c]}$ The valence isomerisation process of $\left[A u^{\prime \prime \prime}\left(P^{\bullet-}\right)\right]$ to $A u^{\prime \prime}(P)$ depends on thermodynamic and kinetic aspects, especially changes in Au-N bond lengths and macrocycle deformation, ${ }^{[13]}$ and is a further key to the long lifetime of charge-shifted states involving gold(III) porphyrins (Scheme 1a).

Homogeneous gold catalysis is dominated by reactions which retain the $+\mathrm{I}$ oxidation state of $\operatorname{gold}(\mathrm{I})$ in the catalytic cycle. ${ }^{[14]} \mathrm{A}$ single report deals with the cycloisomerisation of allenones

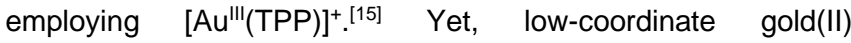
intermediates have been repeatedly suggested as transient intermediates in the context of photochemical gold-catalysed reactions, for instance by Glorius, Hashmi and Toste. ${ }^{[16]}$ However, spectroscopic or structural evidence for low-coordinate gold(II) species in photoredox catalysis is still lacking. The isolable tetracoordinate gold(III/II) porphyrins, however, are well suited for further studies involving the $\mathrm{Au}{ }^{11 / / I}$ redox couple in redox and photoredox processes.

Herein we present the synthesis and properties of three novel

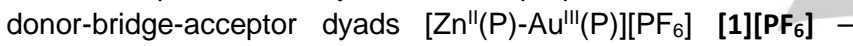
[3][ $\left.\mathrm{PF}_{6}\right]$, designed to undergo rapid photoinduced electron transfer using zinc(II) porphyrin amino acid derivatives as chromophores and electron donors and gold(III) porphyrin amino acid derivatives as electron acceptors connected by a $\pi$ conjugated amide bridge with porphyrin-aryl torsion angles around $50-80^{\circ}$ in the solid state. ${ }^{[49]}$ In order to tune the driving forces of the forward PET and recombination reactions, the individual building blocks bear electron-donating and electronwithdrawing meso-aryl groups $\left(\mathrm{Ar}=4-\mathrm{C}_{6} \mathrm{H}_{4} \mathrm{O}^{n} \mathrm{Bu}, 4-\mathrm{C}_{6} \mathrm{H}_{4} \mathrm{CF}_{3}\right)$. The light-induced charge-shifted states are probed by femtosecond transient absorption spectroscopy and are employed in bimolecular reactions with amines as sacrificial electron donors. The electronic structure of the resulting reduced dyads $Z n^{\prime \prime}(P)-A u^{\prime \prime}(P)$ is elucidated by $X$-band EPR, gold $L_{3}$-edge $X$-ray absorption near edge structure (XANES) and paramagnetic ${ }^{1} \mathrm{H}$ NMR spectroscopy in combination with Density Functional Theory calculations. Finally, $\left[\mathrm{Zn}^{\prime \prime}(\mathrm{P})-\mathrm{Au}^{\prime \prime \prime}(\mathrm{P})\right]^{+}$is employed in a visible-light induced catalytic process.

\section{Results and Discussion}

Syntheses of building blocks, reference compounds and dyads.

The free-base and aurated building blocks la - Illa and [AuIb][PF 6 - [Au-IIlb][PF $]$, as well as the $\mathrm{N}$-acetyl or ester protected zinc(II) and gold(III) reference compounds Zn-Ac-la $\mathrm{Zn}-\mathbf{A c}-\mathrm{IIIa}$ and $[\mathrm{Au}-\mathbf{A c}-\mathrm{Ib}]\left[\mathrm{PF}_{6}\right]$ - [Au-Ac-IIIb][PF 6 were prepared according to literature procedures. ${ }^{[4 g, 13 b, 17]}$ The cationic gold(III) porphyrin acids were easily prepared by metalation of the free-base porphyrins $\mathbf{l b}$ - IIIb with potassium tetrachlorido aurate(III) in the presence of $\mathrm{HOAc/NaOAc}$ according to "Fleischer's route". ${ }^{[18]}$ The synthetic strategy is based on coupling a substitutionally inert, cationic gold(III) porphyrin acid [Au-lb] ${ }^{+}$[Au-IIIb] ${ }^{+}$with a free-base amine-substituted porphyrin la - Illa to give the $\left[\mathrm{Zn} \text { "I }(P)-A u^{\prime \prime \prime}(P)\right]^{+}$dyads $[1]^{+}-[3]^{+}$(Scheme 2 ).
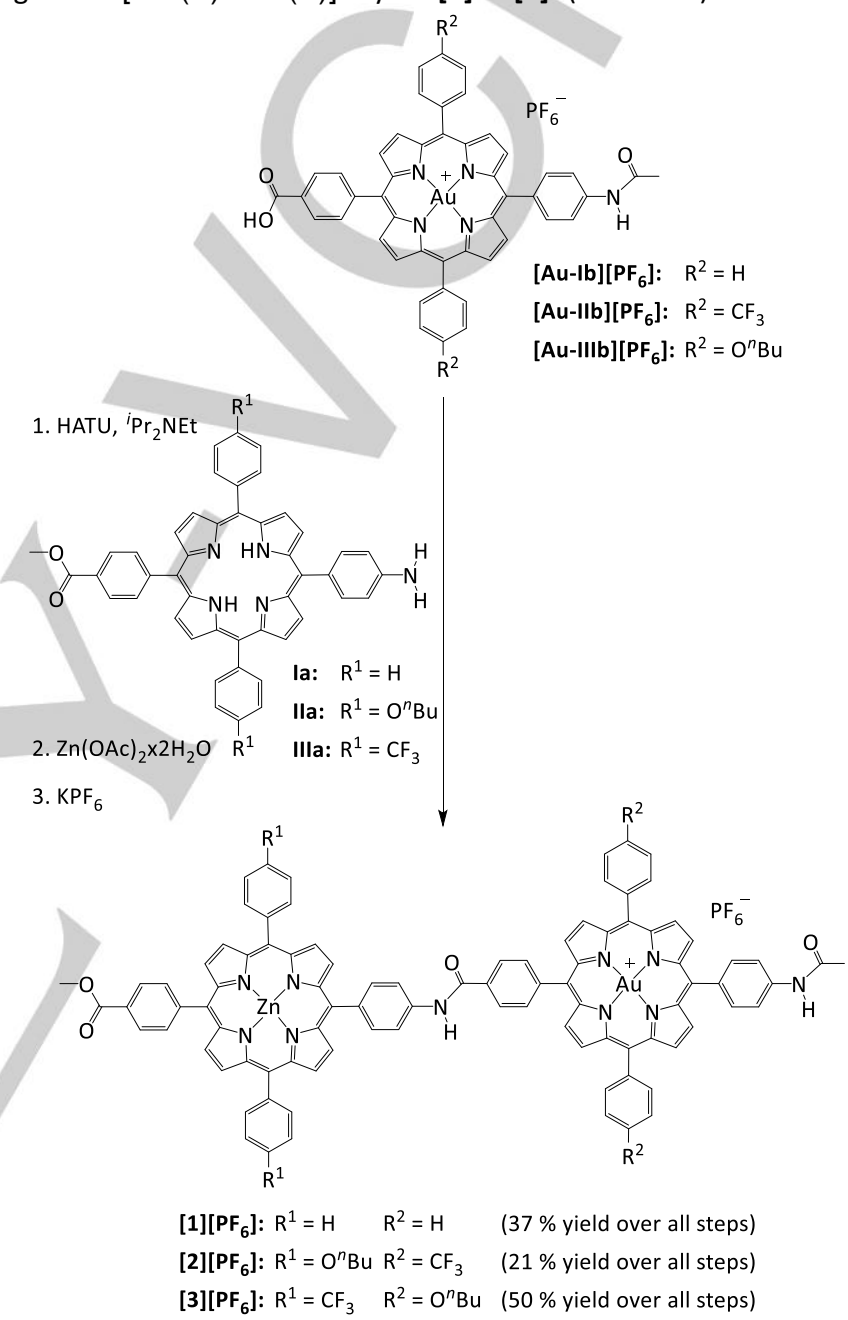

Scheme 2. Synthesis of dyads $[1]\left[\mathrm{PF}_{6}\right]-[3]\left[\mathrm{PF}_{6}\right]$.

Amide formation between the porphyrins is enabled by the coupling reagent HATU (1-[bis(dimethylamino)methylene]-1 $\mathrm{H}$ 1,2,3-triazolo[4,5-b]pyridinium 3-oxide hexafluorophosphate) and DIPEA ( $N, N$-diisopropylethylamine) in DMF. The dyads [1][PF 6 [3][PF 6$]$ were obtained from the free base dyads via metalation with zinc(II) acetate dihydrate and subsequent counterion exchange with $\mathrm{KPF}_{6}$ (Scheme 2).

\section{Characterisation of dyads $[1]\left[\mathrm{PF}_{6}\right]-[3]\left[\mathrm{PF}_{6}\right]$.}

The constitution of dyads [1][PF 6$]-[3]\left[\mathrm{PF}_{6}\right]$ was established via ${ }^{1} \mathrm{H}$ NMR, ${ }^{13} \mathrm{C}$ NMR, ${ }^{31} \mathrm{P}$ NMR and $2 \mathrm{D}$ NMR spectroscopy 
(Supporting Information, Fig. S1 - S8), IR spectroscopy (Supporting Information, Fig. S9 - S11), UV/Vis spectroscopy (Supporting Information, Fig. S12 - S13) and high-resolution mass spectrometry (Supporting Information, Fig. S14 - S16). For solubility reasons, DMF is employed in the NMR studies.

The successful amide formation is clearly substantiated by the appearance of the $\mathrm{NH}$ amide proton resonances at $\delta=11.25-$ $11.29 \mathrm{ppm}$ in the ${ }^{1} \mathrm{H}$ NMR spectra. The terminal $\mathrm{CH}_{3}$ (ester) and $\mathrm{CH}_{3}$ (amide) substituents exhibit characteristic resonances at $\delta=$ $4.11-4.14$ and $2.32-2.34 \mathrm{ppm}$, respectively, in a correct integral ratio. A consequence of the successful metalation with zinc(II) acetate dihydrate is the expected disappearance of the inner pyrrole $\mathrm{NH}$ resonances. The $\left[\mathrm{PF}_{6}\right]^{-}$counterions feature the characteristic septet at $\delta=-144 \mathrm{ppm}$ in the ${ }^{31} \mathrm{P}$ NMR spectra. IR absorption bands for group vibrations appear for the ester and amide substituents at around 1715 and $1668 \mathrm{~cm}^{-1}$, respectively. Absorptions of PF stretching and deformation modes of $\left[\mathrm{PF}_{6}\right]^{-}$ counterions appear at 839 - 841 and $556-557 \mathrm{~cm}^{-1}$, respectively. $\mathrm{ESI}^{+}$mass spectra show the expected signals of the $[1]^{+}$, [2] $^{+}$and [3] ${ }^{+}$cations at $\mathrm{m} / z=1641.3703,1921.4610$, 1921.4605 , respectively, confirming the stability and integrity of the complex cations.

\section{Photophysical properties.}

The electronic absorption spectra of the dyads [1][PF 6 - [3][PF 6 are in good agreement with those of the constituent monoporphyrins displaying similar band maxima and no splitting of Soret or $\mathrm{Q}$ bands. The absorption spectra of [1][PF 6 - [3][PF 6 are essentially a superposition of the unperturbed monoporphyrin spectra, ${ }^{[19]}$ as exemplarily shown for dyad [1][PF 6 in Fig. 1 (Supporting Information, Fig. S12 - S13 for [2][PF $]$ and [3][PF 6 ). This indicates a very weak ground-state electronic interaction between the individual building blocks of the amide-bridged dyads.

The gold(III) porphyrinato reference complexes [Au-Ac-lb][PF $\left.\mathbf{P F}_{6}\right]$ and $[\mathbf{A u}-\mathbf{A c}-\mathrm{Ilb}]\left[\mathrm{PF}_{6}\right]$ show hypsochromically shifted and weaker Soret bands as compared to the reference zinc porphyrins $\mathbf{Z n - A c -}$ la $-\mathbf{Z n}$-Ac-lla representing the $\mathrm{Au}$ and $\mathrm{Zn}$ constituents of dyads $[1]^{+}$and [2]+. This furnishes the characteristic high-energy shoulder on the Soret bands of [1] ${ }^{+}$and [2] ${ }^{+}$(Fig. 1; Supporting Information, Fig. S12). The gold(III) porphyrin [Au-Ac-IIlb] with electron-donating $\mathrm{O}^{n} \mathrm{Bu}$ substituents, however, displays a similar Soret energy as the zinc(II) porphyrin Zn-Ac-Illa with electronwithdrawing $\mathrm{CF}_{3}$ substituents, resulting in a Soret band of [3] ${ }^{+}$ without a shoulder (Supporting Information, Fig. S13). ${ }^{[20]}$ As expected for metalloporphyrins with local $D_{4 \mathrm{~h}}$ symmetry, a reduction of the number of $Q$ bands from four to two is observed in all cases compared to their free-base ancestors with local $D_{2 \mathrm{~h}}$ symmetry. In all cases, the $Q$ bands of the gold(III) porphyrin are at higher energy than those of the corresponding zinc(II) porphyrin (Fig. 1; Supporting Information, Fig. S12 - S13).

The fluorescence maxima, fluorescence quantum yields and the excited state lifetimes of the dyads [1][PF 6$]-[3]\left[\mathrm{PF}_{6}\right]$ and the associated reference zinc porphyrins $\mathbf{Z n - A c - l a ~}-\mathbf{Z n}$-Ac-IIla are summarised in Table 1. Gold(III) porphyrins are non-emissive in fluid solution at room temperature. ${ }^{[20 \mathrm{~b}, 21]}$ This also holds for the reference compounds [Au-Ac-Ib][PF6] - [Au-Ac-IIIb][PF6 (Fig. 1; Supporting Information, Fig. $S 12-S 13)$. Emission energies $\left(S_{1}\right.$ state) of the zinc reference compounds $\mathbf{Z n - A c - l a - Z n - A c - I I l a ~ a n d ~}$ the respective dyads [1][PF $]-[3]\left[\mathrm{PF}_{6}\right]$ are very similar (Fig. 1; Supporting Information, Fig. S12 - S13), confirming that only the zinc porphyrins are emissive. However, the zinc(II) porphyrin $S_{1}$ fluorescence is nearly completely quenched in all dyads irrespective of the meso-substituents $R^{1}$ and $R^{2}$ (> $\left.97 \%\right)$. Similar to comparable dyads ${ }^{[10]}$, depopulation of the fluorescent $S_{1}$ state of $\mathrm{Zn}(\mathrm{P})$ occurs by photoinduced electron transfer towards the appended gold(III) porphyrin resulting in a charge-shifted singlet state ${ }^{1} \mathrm{CSh}$ (and the triplet state ${ }^{3} \mathrm{CSh}$ after intersystem crossing) ${ }^{1,3}\left[\mathrm{Zn}^{\prime \prime}\left(\mathrm{P}^{\bullet+}\right)-A u^{\prime \prime}(\mathrm{P})\right]^{+}$(vide infra). The residual weak fluorescence is associated with a small fraction of unquenched dyads. The driving force for the light-induced electron transfer is estimated from electrochemical data.

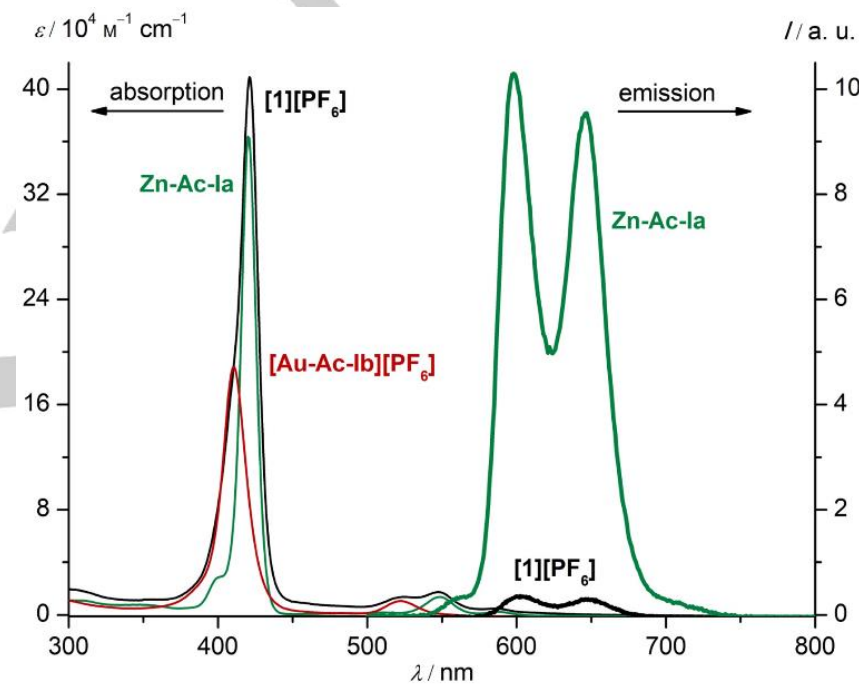

Figure 1. Absorption and emission spectra of [1][PF 6 and constituent monoporphyrins in $\mathrm{CH}_{2} \mathrm{Cl}_{2}$. Excitation wavelength was $421 \mathrm{~nm}$.

Table 1. Fluorescence data of porphyrins in $\mathrm{CH}_{2} \mathrm{Cl}_{2}$ at room temperature.

\begin{tabular}{lcccccc}
\hline & $\mathrm{R}^{1}$ & $\mathrm{R}^{2}$ & $\lambda_{\mathrm{em}} / \mathrm{nm}^{[\mathrm{a}]}$ & $\Phi_{\mathrm{fl}}$ & $\tau / \mathrm{ns}^{[\mathrm{b}]}$ & quenching [\%] \\
\hline Zn-Ac-la & $\mathrm{H}$ & - & 598,648 & 0.1037 & 1.7 & \\
[1][PF $]$ & $\mathrm{H}$ & $\mathrm{H}$ & 599,646 & 0.0029 & 1.6 & 97 \\
Zn-Ac-Ila & $\mathrm{O}^{n} \mathrm{Bu}$ & - & 602,649 & 0.0770 & 1.5 & \\
[2][PF $]$ & $\mathrm{O}^{n} \mathrm{Bu}$ & $\mathrm{CF}_{3}$ & 601,649 & 0.0017 & 1.3 & 98 \\
Zn-Ac-IIla & $\mathrm{CF}_{3}$ & - & 599,644 & 0.1003 & 1.8 & \\
[3][PF6] & $\mathrm{CF}_{3}$ & $\mathrm{O}^{n} \mathrm{Bu}$ & 599,647 & 0.0011 & 1.7 & 99 \\
\hline
\end{tabular}

[a] Excitation wavelength was $421 \mathrm{~nm}$, except for $\mathbf{Z n - A c - I I l a ~ a n d ~ [ 3 ] [ P F 6 ] ~ ( 4 1 8 ~}$ $n \mathrm{~nm}) .{ }^{[b]}$ All decays are monoexponential.

\section{Electrochemical investigations.}

During sequential one-electron redox reactions, porphyrin macrocycles generally exhibit two reversible oxidations, which lead to the $\pi$ cation radical and the porphyrin dication, whereas reversible reductions yield the $\pi$ anion radical and the porphyrin dianion. This also includes metalloporphyrins with coordinated 
redox-inert metal ions, such as $\mathrm{Mg}^{2+}\left(\mathrm{d}^{0}\right)$ or $\mathrm{Zn}^{2+}\left(\mathrm{d}^{10}\right)$. The situation can change in the presence of a "non-innocent" metal ion like $\mathrm{Au}^{3+}\left(\mathrm{d}^{8}\right)$ with an empty $\mathrm{d}_{\mathrm{x} 2 \mathrm{y} 2 \mathrm{y}}$ orbital. In gold(III) porphyrins, the initial gold-based reduction is followed by a porphyrin-based reduction. ${ }^{[10,12,13]}$ The individual redox potentials of the dyads [1] $\left[\mathrm{PF}_{6}\right]-[3]\left[\mathrm{PF}_{6}\right]$ are close to those of the respective reference zinc and gold porphyrins Zn-Ac-la - Zn-Ac-Illa and [Au-Ac$\mathrm{Ib}]\left[\mathrm{PF}_{6}\right]$ - [Au-Ac-Ilb][PF 6 (Fig. 2; Supporting Information, Fig. S17 - S19) indicating the absence of ground state interactions between the zinc(II) porphyrin chromophores and the attached gold(III) porphyrin acceptors (Table 2). $\left.{ }^{49}\right]$ Furthermore, the negligible shift of the first reduction of the mononuclear gold(III) porphyrins and the corresponding dyads is in agreement with a metal-based mechanism that is only weakly affected by the appended chromophore. ${ }^{[9 e, 10 c]}$ This behaviour is exemplarily illustrated in Fig. 2 displaying the cyclic voltammograms of dyad [2][PF 6 and associated "building-blocks" Zn-Ac-Ila and [Au-Ac$\mathrm{Ilb}]\left[\mathrm{PF}_{6}\right]$.

Table 2. Redox potentials of reference compounds Zn-Ac-la - Zn-Ac-IIla, [AuAc-lb][PF 6 - $[\mathbf{A u}-\mathbf{A c - I I I b}]\left[\mathrm{PF}_{6}\right]$ and dyads $[1]\left[\mathrm{PF}_{6}\right]-[3]\left[\mathrm{PF}_{6}\right]$ in $0.1 \mathrm{M}$ $\left[{ }^{n} \mathrm{Bu}_{4} \mathrm{~N}\right]\left[\mathrm{PF}_{6}\right] / \mathrm{THF}$ solution, potentials given in $\mathrm{V}$ relative to the ferrocene/ferrocenium couple.

\begin{tabular}{|c|c|c|c|c|c|}
\hline & $\begin{array}{c}E_{1 / 2}(\mathrm{P} / \mathrm{Zn}) \\
\left(\mathrm{ox}^{2}\right)\end{array}$ & $\begin{array}{c}E_{1 / 2}(\mathrm{P} / \mathrm{Zn}) \\
\left(\mathrm{ox}^{1}\right)\end{array}$ & $\begin{array}{c}E_{1 / 2}\left(\mathrm{Au}^{I I I / I I}\right) \\
\left(\operatorname{red}^{0}\right) \\
\end{array}$ & $\begin{array}{c}E_{1 / 2}(\mathrm{P} / \mathrm{Au}) \\
\left(\mathrm{red}^{1}\right)\end{array}$ & $\begin{array}{c}E_{1 / 2}(\mathrm{P} / \mathrm{Zn}) \\
\left(\mathrm{red}^{2}\right)\end{array}$ \\
\hline Zn-Ac-la & {$[\mathrm{b}]$} & 0.40 & - & - & -1.78 \\
\hline$[\mathrm{Au}-\mathrm{Ac}-\mathrm{Ib}]\left[\mathrm{PF}_{6}\right]^{[\mathrm{a}]}$ & - & - & -0.96 & -1.44 & - \\
\hline$[1]\left[\mathrm{PF}_{6}\right]$ & [b] & 0.42 & -0.95 & -1.44 & -1.77 \\
\hline Zn-Ac-Ila & 0.71 & 0.35 & - & - & -1.93 \\
\hline$[\mathrm{Au}-\mathrm{Ac}-\mathrm{Ilb}]\left[\mathrm{PF}_{6}\right]$ & - & - & -0.91 & -1.55 & - \\
\hline$[2]\left[P_{6}\right]$ & 0.68 & 0.33 & -0.92 & -1.53 & -1.93 \\
\hline Zn-Ac-IIla & [b] & 0.49 & - & 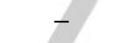 & -1.85 \\
\hline [Au-Ac-IIIb][PF $]$ & - & - & -0.98 & -1.64 & \\
\hline$[3]\left[P_{6}\right]$ & [b] & 0.49 & -0.99 & -1.63 & -1.83 \\
\hline
\end{tabular}

[a] In DMF. [b] Outside solvent window.
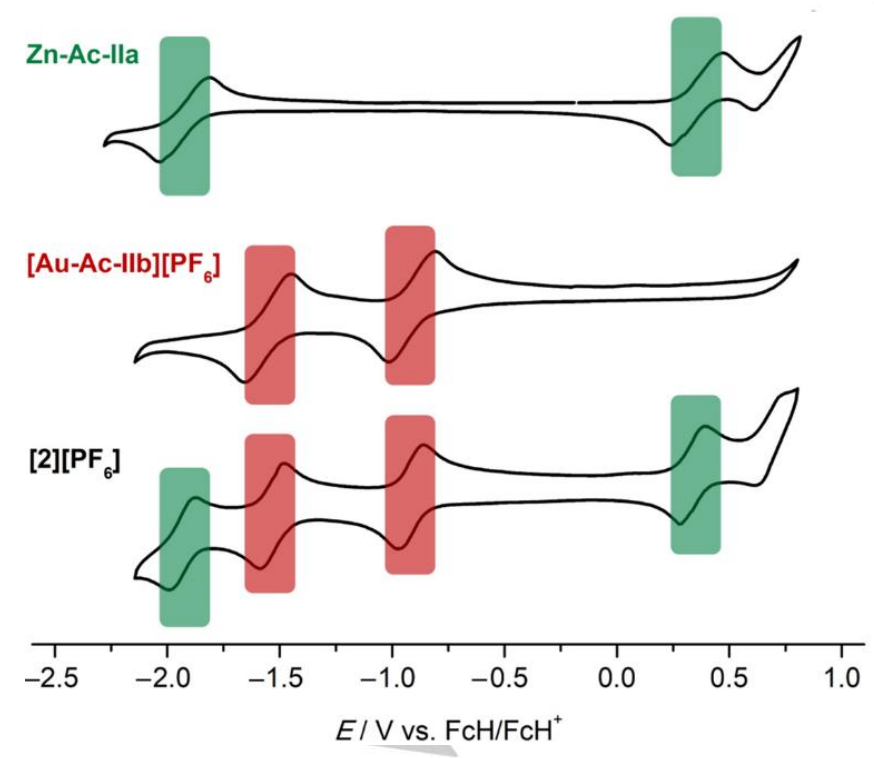

Figure 2. Cyclic voltammograms of $\mathrm{Zn-Ac-Ila,} \mathrm{[Au-Ac-Ilb]}\left[\mathrm{PF}_{6}\right]$ and dyad [2] $\left[\mathrm{PF}_{6}\right]$ in $0.1 \mathrm{M}\left[{ }^{n} \mathrm{Bu}_{4} \mathrm{~N}\right]\left[\mathrm{PF}_{6}\right] / \mathrm{THF}$ solution.

The meso-aryl substituents generally induce an anodic shift of the first oxidation and reduction potentials in the series $\mathrm{R}=\mathrm{O}^{n} \mathrm{Bu}>\mathrm{H}$ $>\mathrm{CF}_{3} \cdot{ }^{19}$ The shifts amount up to $0.14 \mathrm{~V}$ for the first ligand-centred oxidation (ox $\left.{ }^{1}\right)$ from $\mathbf{Z n - A c - I l a ~}\left(\mathrm{R}^{1}=\mathrm{O}^{n} \mathrm{Bu}\right)$ to $\mathbf{Z n - A c - I l l a ~}\left(\mathrm{R}^{1}=\right.$ $\left.\mathrm{CF}_{3}\right)$ and $0.07 \mathrm{~V}$ for the first metal-centred reduction $\left(\right.$ red $\left.^{0}\right)$ from [Au-Ac-IIlb][PF $]\left(R=\mathrm{O}^{n} \mathrm{Bu}\right)$ to [Au-Ac-Ilb][PF 6$]\left(R=\mathrm{CF}_{3}\right)$. The differences between the gold-centred and subsequent ligandcentred reduction of the respective dyads amount to $0.49-0.64$ $\mathrm{V}$. This translates to high comproportionation constants of $K_{\mathrm{c}}>$ $10^{10}$ for the neutral gold(II) complexes. ${ }^{[13,22]}$ Therefore, disproportionation of neutral dyads $\mathrm{Zn}(\mathrm{P})-\mathrm{Au}^{\prime \prime}(\mathrm{P})$ (prepared electrochemically, chemically or photochemically) can be ruled out and all spectral signatures after one-electron reduction will be associated with the neutral $\mathrm{Zn}(\mathrm{P})-\mathrm{Au}{ }^{\prime \prime}(\mathrm{P})$ dyads. ${ }^{[13 b]}$

Table 3. Energies of the porphyrin $S_{1}(\mathrm{Zn})$ and ${ }^{1,3} \mathrm{CSh}$ states, as well as rate constants and driving forces for the three dyads.

\begin{tabular}{lcccccc}
\hline & $\begin{array}{c}E\left(\mathrm{~S}_{0} \rightarrow \mathrm{S}_{1}\right) \\
(\mathrm{Zn})[\mathrm{eV}]\end{array}$ & $\begin{array}{c}\left.E^{1,3} \mathrm{CSh}\right) \\
{[\mathrm{eV}]}\end{array}$ & $\begin{array}{c}k_{\mathrm{ET} 1 / \mathrm{HT} 1} \\
{\left[\mathrm{~s}^{-1}\right]}\end{array}$ & $\begin{array}{c}\Delta G^{0} \mathrm{ET} 1 \\
{[\mathrm{eV}]}\end{array}$ & $\begin{array}{c}k_{\mathrm{BET} 1} \\
{\left[\mathrm{~s}^{-1}\right]}\end{array}$ & $\begin{array}{c}k_{\mathrm{BET} 2} \\
{\left[\mathrm{~s}^{-1}\right]}\end{array}$ \\
\hline$[1]\left[\mathrm{PF}_{6}\right]$ & 2.07 & 1.37 & $4.8 \times 10^{10}$ & -0.70 & $8.3 \times 10^{9}$ & $3.3 \times 10^{8}$ \\
{$[2]\left[\mathrm{PF}_{6}\right]$} & 2.06 & 1.25 & $8.3 \times 10^{10}$ & -0.81 & $12.2 \times 10^{9}$ & $3.3 \times 10^{8}$ \\
{$[3]\left[\mathrm{PF}_{6}\right]$} & 2.07 & 1.48 & - & -0.59 & $3.4 \times 10^{9}$ & $2.9 \times 10^{8}$
\end{tabular}

\section{Energy diagrams of the dyads.}

The fluorescence data (Table 1) along with the electrochemical data (Table 2) enable assessing the free energy changes of the photoinduced electron transfer from the zinc(II) porphyrin's first singlet excited state $\left(S_{1}\right)$ to the corresponding gold(III) porphyrin $\left(\Delta G_{E T}^{\circ}\right)$ and of the subsequent back electron transfer to restore the ground state $\left(-E\left({ }^{1,3} \mathrm{CSh}\right)\right.$; Table 3$)$.

As these are merely charge-shift reactions (CSh) without charge separation, the simplified Rehm-Weller equation ${ }^{[23]}$ is used neglecting a Coulomb interaction term to estimate the energy of the CSh state(s). As illustrated in Table 3, the driving force for photoinduced electron transfer $\left(\Delta G_{\mathrm{ET}}^{\circ}\right)$ increases in the series [2] ${ }^{+}$ $>[1]^{+}>[3]^{+}$in accordance with the electron donating and withdrawing effects of the meso-aryl substituents. Concomitantly, the driving force for the back electron transfer $\left(-E\left({ }^{1,3} \mathrm{CSh}\right)\right)$ increases in the series $[3]^{+}>[1]^{+}>[2]^{+}$. With the free Gibbs energies between -1.25 and $-1.48 \mathrm{eV}$, the BET processes are likely to be in the Marcus inverted region. ${ }^{[10 d, 24]}$

A simplified and generalised energy level diagram of [ $\mathrm{Zn}$ " $(\mathrm{P})$ $\left.\mathrm{Au}^{\prime \prime \prime}(\mathrm{P})\right]^{+}$dyads upon photoexcitation is illustrated in Fig. 3. The zinc(II) porphyrin and gold(III) porphyrin excited singlet states $\mathrm{S}_{1}(\mathrm{Zn} / \mathrm{Au})$ and $\mathrm{S}_{2}(\mathrm{Zn} / \mathrm{Au})$ are determined from emission and absorption spectroscopic data (Table 3, Supporting Information, Exp. Section). The zinc and gold porphyrin triplet state energies $T_{1}(\mathrm{Zn})$ and $T_{1}(\mathrm{Au})$ are estimated from literature data. The triplet energies of zinc(II) porphyrins range from $1.41 \mathrm{eV}$ to $1.81 \mathrm{eV}$, ${ }^{[25]}$ those of gold(III) porphyrins from $1.75 \mathrm{eV}$ to $1.82 \mathrm{eV} .^{[8 \mathrm{e}, 21 \mathrm{~b}, 26]}$ Both depend slightly on the substitution pattern and the solvent. The final charge shifted states ${ }^{1,3}\left[\mathrm{Zn}^{\prime \prime}\left(\mathrm{P}^{\bullet+}\right)-A u^{\prime \prime}(\mathrm{P})\right]^{+} \quad\left({ }^{1,3} \mathrm{CSh}\right)$ are calculated from the electrochemical data (Table 3 ). A significant energy difference between singlet and triplet charge-shifted 
states ${ }^{1} \mathrm{CSh}$ and ${ }^{3} \mathrm{CSh}$ is not expected considering the large distance of the spin centres. In fact, the unpaired electrons should be essentially uncoupled in the CSh states. The energies of the intermediate charge shifted states ${ }^{1,3}\left[\mathrm{Zn}^{\prime \prime}\left(\mathrm{P}^{\bullet+}\right)-\mathrm{Au}^{\mathrm{III}}\left(\mathrm{P}^{\bullet-}\right)\right]^{+}$, populated directly after the electron transfer from the $\pi$-HOMO of the $\mathrm{Zn}(\mathrm{P})$ to the $\pi$-LUMO of the $\mathrm{Au}$ 'II'(P) moiety, are not experimentally accessible. However, quantum chemical calculations place these states above the ${ }^{1,3}\left[\mathrm{Zn}^{\prime \prime}\left(\mathrm{P}^{\bullet+}\right)-A u^{\prime \prime}(\mathrm{P})\right]^{+}$ valence isomeric state in agreement with the gold(II) nature of the final ${ }^{1,3} \mathrm{CSh}$ states (see below; ESI).[13] Irradiating at the Soret band energies, in principle both sites of the dyad can be excited as seen in Fig. 1. Starting with excitation of the $Z n(P)$ site, the $S_{2}(Z n)$ state of $Z n(P)$ is populated. The driving force of PET from the $S_{2}(Z n)$ state to yield the charge-shifted states is very high, placing these reactions in the Marcus inverted region. ${ }^{24}$ Consequently, internal conversion (IC) from the $S_{2}(Z n)$ to the $\mathrm{S}_{1}(\mathrm{Zn})$ state should dominate $\left(k_{\mathrm{IC}(Z n)}\right)$. In principle, energy transfer from the $S_{1}(Z n)$ to the $S_{1}(A u)$ state can occur but this is slightly uphill and therefore excluded from Fig. 3 . The $S_{1}(Z n)$ state can undergo ISC to the zinc porphyrin triplet state $\left[{ }^{3} \mathrm{Zn} \text { "I }(\mathrm{P})-\mathrm{Au}^{\prime \prime \prime}(\mathrm{P})\right]^{+}$ $\left(\mathrm{T}_{1}(\mathrm{Zn}) ; k_{\mathrm{ISC}(\mathrm{Zn})}\right)$ or give the CSh state(s) by electron transfer $\left(k_{\mathrm{ET} 1}\right)$. The $T_{1}(Z n)$ state is also above the CSh state(s) and hence, electron transfer yielding ${ }^{3} \mathrm{CSh}$ states from $\mathrm{T}_{1}(\mathrm{Zn})$ is conceivable as well $\left(k_{\mathrm{ET} T 2}\right)$.

Excitation of the gold porphyrin site at the Soret band should yield the $S_{2}(A u)$ state of the gold porphyrin. This $S_{2}(A u)$ state should undergo efficient internal conversion to the $S_{1}(\mathrm{Au})$ state $\left(k_{\mathrm{IC}(\mathrm{Au})}\right)$ similar to the zinc site. Based on the efficient spin-orbit coupling enabled by the gold atom, rapid ISC to the gold porphyrin triplet state $T_{1}(\mathrm{Au})$ occurs in a few hundred femtoseconds $\left(K_{\mathrm{ISC}(\mathrm{Au})}\right){ }^{[21 \mathrm{~b}, 26]}$ Triplet-triplet energy transfer from the $T_{1}(A u)$ to the $T_{1}(Z n)$ state is slightly downhill by ca. $0.2 \mathrm{eV}^{[8,26]}$ and therefore conceivable (not shown in Fig. 3 for clarity). ${ }^{[27]}$ Hole-transfer from $S_{1}(\mathrm{Au})$ and $\mathrm{T}_{1}(\mathrm{Au})$ states to give the CSh state(s) is thermodynamically feasible as well $\left(k_{\mathrm{HT}_{1}}, k_{\mathrm{HT}_{2}}\right)$. In any case, the CSh states are well below the $S_{1}$ and $T_{1}$ states of both metalloporphyrins and are in principle accessible via diverse pathways.

(Figure 3 see end of manuscript)

Figure 3. Energy level diagram of dyads $[1]\left[\mathrm{PF}_{6}\right]-[3]\left[\mathrm{PF}_{6}\right]$ including triplet and charge-shifted states. Abbreviations: $\mathrm{CSh}=$ charge-shift, $\mathrm{ET}=$ electron transfer, $\mathrm{HT}$ = hole transfer, $\mathrm{BET}$ = back electron transfer, $\mathrm{IC}=$ internal conversion, ISC = intersystem crossing.

\section{Time-resolved spectroscopy. \\ emission and transient \\ absorption}

Excitation of [1][PF6] - [3][PF6] at $410 \mathrm{~nm}$ in THF results in weak fluorescence from the $S_{1}(Z n)$ state (Fig. 1, Table 1). Applying time-resolved photoluminescence reveals that the emission follows a monoexponential decay law in all cases. The corresponding emission lifetimes are similar to the lifetimes of the respective zinc(II) porphyrin references $\mathbf{Z n - A c - l a ~ - ~ Z n - A c - I I l a ~}$ (Table 1, Supporting Information, Figure S20). However, the much lower fluorescence quantum yield of [1][PF $]-[3]\left[\mathrm{PF}_{6}\right]$ indicates that only a minority of the excited population ends up in the minimum of the $S_{1}$ state while the majority is quenched by an ultrafast decay to a non-emissive state. This decay is faster than the time resolution of the instrument of $50 \mathrm{ps}$. We assign this ultrafast decay to the electron transfer yielding the CSh state(s) (KET1/HT1 $>10^{10} \mathrm{~s}^{-1}$, in the Marcus normal region). ${ }^{[24]}$ Consequently, most of the observed residual steady-state emission of the dyads arises from a small, unquenched fraction of the $S_{1}$ state population.

In order to track the evolution of the non-emissive states $\left(\mathrm{S}_{1}(\mathrm{Au})\right.$, $\mathrm{T}_{1}(\mathrm{Zn}) ; \mathrm{T}_{1}(\mathrm{Au})$ and $\left.{ }^{1,3} \mathrm{CSh}\right)$, pump-probe transient absorption (TA) spectroscopy was employed in the fs-ns time regime. The TA spectra of [1][PF 6 in THF $0.3-1400$ ps after excitation with a $400 \mathrm{~nm}$ pulse are depicted in Fig. 4a. The TA spectra of the dyads [2] $\left[\mathrm{PF}_{6}\right]$ and $[3]\left[\mathrm{PF}_{6}\right]$ and their dynamics are basically similar to that of [1][PF 6$]$ (Supporting Information, Fig. S21).
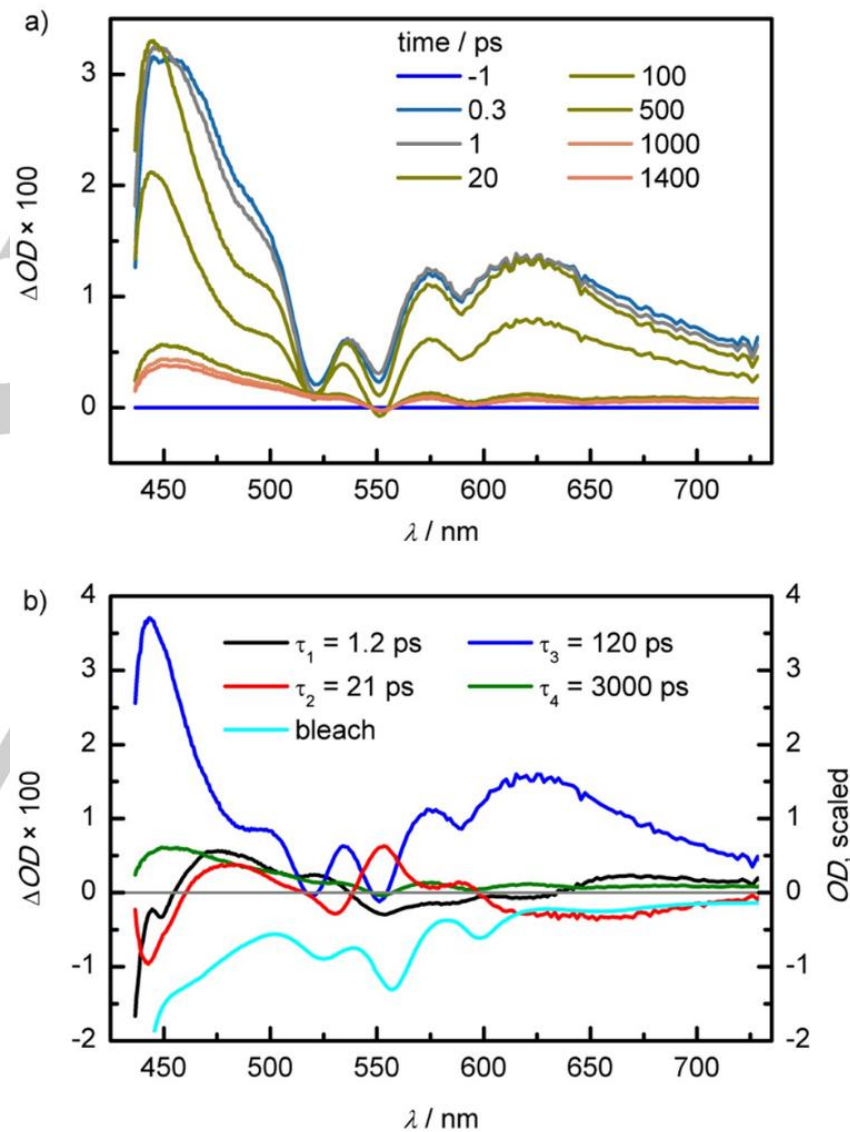

Figure 4. a) fs-TA spectra of [1] $\left[\mathrm{PF}_{6}\right]$ in THF at room temperature at different time points after excitation with $400 \mathrm{~nm}$ and b) amplitude spectra of the components labelled with the respective time constants.

The TA spectra of [1] ${ }^{+}$show three characteristic local minima at 522, 551 and $591 \mathrm{~nm}$. These are assigned to the combined $Q$ band ground state bleaches of the zinc(II) and gold(III) porphyrin (Fig. 1). Obviously, the $400 \mathrm{~nm}$ pulse excites both the zinc and the gold site as discussed above $\left(S_{2}(Z n), S_{1}(Z n), S_{2}(A u), S_{1}(A u)\right)$ and excited states from both sites are likely observable. Indeed, the excited state absorption (ESA) at $575 \mathrm{~nm}$ can be assigned to 
the $T_{1}(\mathrm{Zn})$ state ${ }^{[28]}$, whereas the broad ESA between $590-650$ $n m$ is a feature of the $T_{1}(A u)$ state. ${ }^{[29]}$ With this assignment, the local triplet states $T_{1}(\mathrm{Zn})$ and $T_{1}(\mathrm{Au})$ are populated in the subpicosecond time scale. After $1 \mathrm{~ns}$, features of a long-lived state $(\tau$ $=3.0 \mathrm{~ns})$ reminiscent of those of the cation radical $\left[\mathrm{Zn}\left(\mathrm{TPP}^{\bullet+}\right)\right]^{+}$ remain. ${ }^{[30]}$ As the $A u^{\prime \prime}(P)$ absorption spectra are similar to the $\left[A u^{\prime \prime \prime}(P)\right]^{+}$spectra, ${ }^{13 b}$ the ${ }^{1,3} \mathrm{CSh}$ state is essentially manifested by the $\left[\mathrm{Zn}\left(\mathrm{P}^{\bullet+}\right)\right]^{+}$characteristics. Hence, the long-lived excited state is assigned to the ${ }^{1,3} \mathrm{CSh}$ state(s). Typical lifetimes of ${ }^{3} \mathrm{Zn}(\mathrm{P})$ and $\left.{ }^{3} \mathrm{Au} \mathrm{u}^{\mathrm{II}}(\mathrm{P})\right]^{+}$triplet states are in the millisecond range. ${ }^{[21 \mathrm{~b}, 28]}$ The significantly reduced lifetimes of these triplet states in the dyad (< $1 \mathrm{~ns})$ suggest an efficient decay path for both the $T_{1}(\mathrm{Zn})$ and $\mathrm{T}_{1}(\mathrm{Au})$ states, namely the final population of the lower lying ${ }^{1,3} \mathrm{CSh}$ state(s). Consequently, all excitation pathways can converge to the same final charge-shifted state ${ }^{1,3}\left[\mathrm{Zn}^{\prime \prime}\left(\mathrm{P}^{\bullet+}\right)-A u^{\prime \prime}(\mathrm{P})\right]^{+}$.

To analyse the TA data more quantitatively, a multiexponential global fit was applied. Four exponential components had to be included in order to reproduce the measured data. Figure $4 \mathrm{~b}$ shows the obtained amplitude spectra of these components labelled by the respective time constants resulting from the fit. The fastest component has a time constant of $1.2 \mathrm{ps}$ and its amplitude spectrum (black line) is not very strong and unspecific. The time scale is slightly faster than the internal conversion from the $S_{2}$, which is originally populated by excitation at the Soret band, to the $S_{1}$ state in $\mathrm{Zn}$ and Au porphyrins. In the dyad this process can be accelerated by the higher density of states or energy redistribution processes contribute to the observed dynamics. The amplitude spectrum of the second exponential component (red line), which has a time constant of 21 ps, exhibits characteristic features in the spectral region of the $Q$ bands of the ground state absorption. In particular, the positive feature at about $555 \mathrm{~nm}$ indicates that the bleach of the zinc porphyrin site becomes stronger. The applied pump pulses at $400 \mathrm{~nm}$ preferentially excite the gold porphyrin site (Fig. 1) but the population of the CSh state changes also the electronic configuration on the zinc side. We therefore assign the $21 \mathrm{ps}$ time constant to the formation of the CSh state(s) $\left(k_{\mathrm{ET} 1 / \mathrm{HT} 1}\right.$, Table 3 , Fig. 3 ) and a corresponding depopulation of the ground state of the zinc porphyrin. The component with a time constant of 120 ps (blue line) corresponds to a strong decrease of the excited state absorption and shows in addition the bleach features of the $Q$ bands. It reflects relaxation of the excited states back to the electronic ground state $\left(k_{\mathrm{BET} 1}\right.$, Table 3 , Fig. 3 ). Its strength indicates that the majority of the excited molecules takes part. However, a significant fraction of the excited dyads remains in a longer living excited state which is responsible for the fourth component (green line) and which relaxes with a time constant of $3 \mathrm{~ns}$. It is assigned to a CSh state, namely the $\left[\mathrm{Zn}^{\prime \prime}\left(\mathrm{P}^{\bullet+}\right)-A u^{\prime \prime}(\mathrm{P})\right]^{+}$ state, probably with triplet character or featuring essentially uncorrelated paramagnetic centres. Back electron transfer from this state is rather slow with $k_{\mathrm{BET} 2}=3.3 \times 10^{8} \mathrm{~s}^{-1}$ (Table 3 ).

In dyad [2][PF 6 , the time for the formation of the CSh state was determined to 12 ps following the same line of arguments (Table 3, Supporting Information, Fig. S21). The driving force for the electron transfer increases from [1] ${ }^{+}$to [2] ${ }^{+}$(Table 3 ) which is in line with the faster formation rate of the CSh state in [2][PF 6$]$ compared to $[1]\left[\mathrm{PF}_{6}\right]$. Recombination of the initial CSh state yielding the ground state is faster than for [1][PF6] due to the smaller driving force (Marcus inverted region; Table 3). For dyad [3][PF 6 , it is difficult to extract the $k_{\mathrm{ET} 1 / \mathrm{HT} 1}$ rate since both porphyrin sites are about equally strongly excited due to the overlapping Soret bands and the feature associated with a delayed excitation of the zinc porphyrin is missing (Supporting Information, Fig. S21).

In all cases, back-electron transfer from the CSh state ${ }^{1,3}\left[\mathrm{Zn}{ }^{11}\left(\mathrm{P}^{\bullet+}\right)\right.$ $\left.\mathrm{Au}^{\prime \prime}(\mathrm{P})\right]^{+}$is significantly slower than the forward electron transfer $\left(k_{\mathrm{BET} 2} \ll<k_{\mathrm{ET} 1 / \mathrm{HT} 1}\right)$ and the recombination from the initial CSh state ${ }^{1,3}\left[\mathrm{Zn}^{\mathrm{II}}\left(\mathrm{P}^{\bullet+}\right)-\mathrm{Au}^{\mathrm{III}}\left(\mathrm{P}^{\bullet-}\right)\right]^{+}\left(k_{\mathrm{BET} 2}<k_{\mathrm{BET} 1}\right)$ (Table 3). The decreasing recombination rate $k_{\mathrm{BET} 2}$ correlates with the increasing driving force for BET in the series [2] ${ }^{+}>[1]^{+}>[3]^{+}$(Table 3) in accordance with the BET occurring in the Marcus inverted region. In addition, the weak electronic coupling due to the mismatched symmetry of the wavefunctions hampers the recombination. ${ }^{[10 d, 12 b, 24]}$ In fact, the electron is located in a goldbased $\sigma$-type $5 d_{x 2-y 2}$ orbital in the final CSh state, but in a $\pi$-orbital of the zinc porphyrin in the ground state. This molecular orbital point of view will be discussed next.

\section{Quantum chemical calculations.}

To confirm the excited state ordering in Fig. 3 and to pin down the electronic nature of the intermediate triplet and charge-shifted states, Density Functional Theory (DFT) calculations have been conducted on the ground state, the $T_{1}(\mathrm{Zn})$ state, the intermediate charge shifted state ${ }^{3}\left[\mathrm{Zn}^{\prime \prime}\left(\mathrm{P}^{\cdot+}\right)-\mathrm{Au}^{\text {III }}\left(\mathrm{P}^{\bullet-}\right)\right]^{+}$and the final ${ }^{3} \mathrm{CSh}$ state ${ }^{3}\left[\mathrm{Zn}{ }^{\prime \prime}\left(\mathrm{P}^{\bullet+}\right)-A u^{\prime \prime}(\mathrm{P})\right]^{+}$of []$^{+}$(Fig. 5). Gratifyingly, all calculations converged to local minima on the respective potential energy surface. 


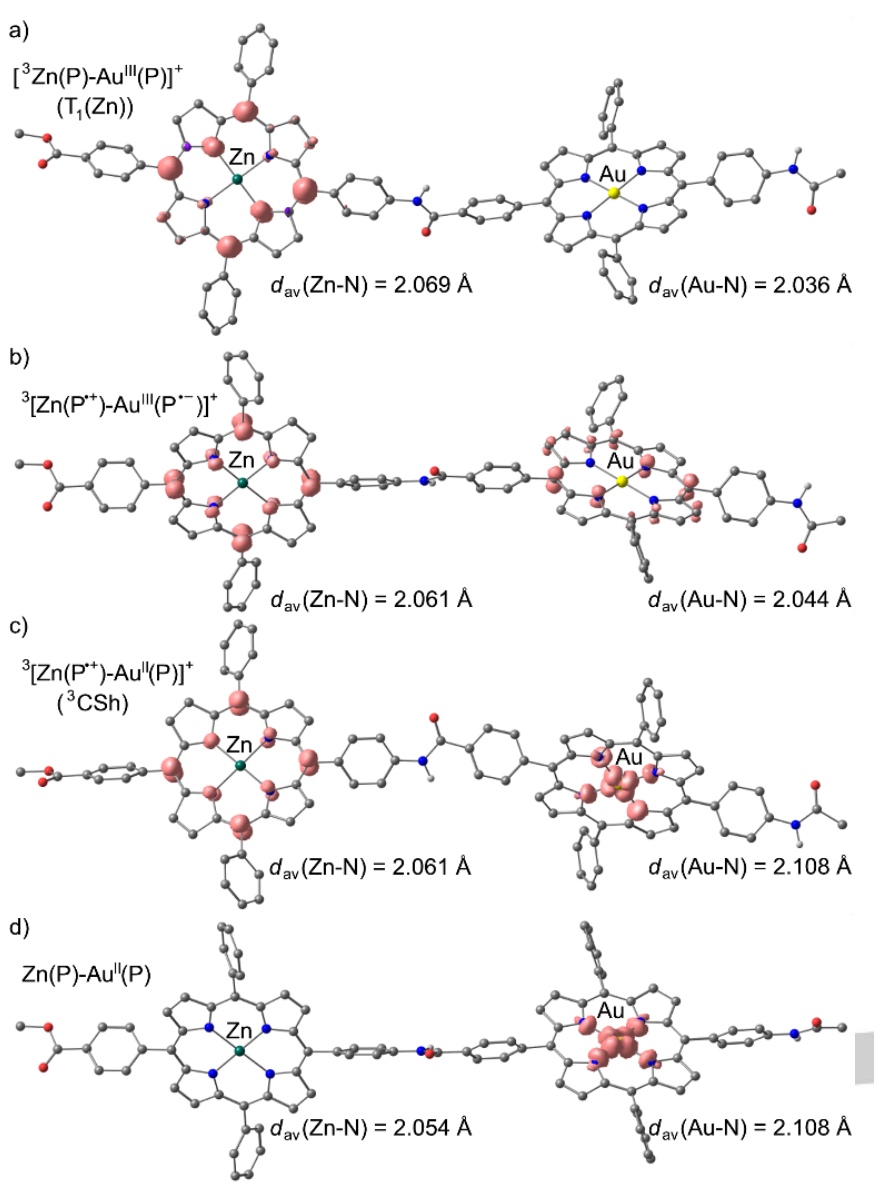

Figure 5. DFT optimised geometries and calculated spin densities of a) the local triplet state of the zinc porphyrin $\left[{ }^{3} \mathrm{Zn}(\mathrm{P})-\mathrm{Au}^{\mathrm{III}}(\mathrm{P})\right]^{+}$, b) the intermediate chargeshifted state $\left.{ }^{3}\left[\mathrm{Zn}\left(\mathrm{P}^{\bullet+}\right)-\mathrm{Au}^{\prime \prime \prime}\left(\mathrm{P}^{\bullet-}\right)\right]^{+}, \mathrm{C}\right)$ the final ${ }^{3} \mathrm{CSh}$ state ${ }^{3}\left[\mathrm{Zn}\left(\mathrm{P}^{\bullet+}\right)-\mathrm{Au}^{\prime \prime}(\mathrm{P})\right]^{+}$of $[1]^{+}$ and d) $\mathrm{Zn}(\mathrm{P})-\mathrm{Au}^{\prime \prime}(\mathrm{P})$. Isosurfaces in pale red at a value of 0.008 a.u.; $\mathrm{CH}$ hydrogen atoms omitted.

The energies of the triplets are comparably close and we refrain from discussing these energy differences. However, we note, that the ${ }^{3}\left[\mathrm{Zn}^{\prime \prime}\left(\mathrm{P}^{\bullet+}\right)-A u^{\prime \prime}(\mathrm{P})\right]^{+}$state is lower in energy than the ${ }^{3}\left[\mathrm{Zn}^{\prime \prime}\left(\mathrm{P}^{\bullet+}\right)-\right.$ $\left.A u^{\prime \prime \prime}\left(P^{\bullet-}\right)\right]^{+}$state which fits to the observed stability of $A u^{\prime \prime}(P)$ over $A u^{\text {III }}\left(\mathrm{P}^{\bullet-}\right) .^{[13 a]}$ Additionally, the DFT calculations reproduce the second-order Jahn-Teller distortion of the gold(II) tetraphenylporphyrin with $\Delta d(\mathrm{Au}-\mathrm{N})=0.016 \AA$ and a bending of two trans positioned pyrrole rings of $\tau=168.7^{\circ}$ similar to the reported parent Au"(TPP) complex. ${ }^{[13 a]}$

Population of the $T_{1}(Z n)$ state increases the $\mathrm{Zn}-\mathrm{N}$ bond lengths from $2.054 \AA$ (ground state) to $2.069 \AA$ but leaves the $A u-N$ distances unaffected $\left(d_{\mathrm{av}}(\mathrm{Au}-\mathrm{N})=2.032 / 2.036 \AA \AA\right.$; ground state $\left./ T_{1}(Z n)\right)$. After electron transfer to the gold porphyrin site, the $\mathrm{Zn}-\mathrm{N}$ bond lengths are slightly reduced and the Au-N distances slightly elongated (Fig. 5b). Valence isomerisation from ${ }^{3}\left[\mathrm{Zn}^{\prime \prime}\left(\mathrm{P}^{\bullet+}\right)\right.$ $\left.A u^{\prime \prime \prime}\left(P^{\bullet-}\right)\right]^{+}$to ${ }^{3}\left[\mathrm{Zn}^{\prime \prime}\left(\mathrm{P}^{\bullet+}\right)-A u^{\prime \prime}(\mathrm{P})\right]^{+}$merely affects the gold porphyrin site significantly elongating the Au-N distances as expected for a gold(II) ion (Fig. 5c). ${ }^{[13 a]}$ These geometrical changes contribute to the reorganisation energy of the valence isomerisation. Basically, the $\mathrm{Au}-\mathrm{N}$ distances increase during the reaction cascade from $A u^{\prime \prime \prime}(P)$ over $A u^{\prime \prime \prime}\left(P^{\bullet-}\right)$ to $A u^{\prime \prime}(P)$ (Fig. $\left.5 a-5 c\right)$.

The local spin density of the $Z n$ porphyrin subunits in both chargeshifted states ${ }^{3}\left[\mathrm{Zn}^{\prime \prime}\left(\mathrm{P}^{\bullet+}\right)-A u^{\prime \prime \prime}\left(\mathrm{P}^{\bullet-}\right)\right]^{+}$and ${ }^{3}\left[\mathrm{Zn}^{\prime \prime}\left(\mathrm{P}^{\bullet+}\right)-A u^{\prime \prime}(\mathrm{P})\right]^{+}$is located in the $\pi$ system (Fig. 5b, 5c). The local symmetry is of $\mathrm{a}_{2 u}$ character (in the standard Gouterman's orbital model ${ }^{[20]}$ ) featuring large coefficients at the meso positions. On the gold porphyrin site, the accepting orbital is one of the $e_{g}$ LUMOs (in the standard Gouterman's orbital model) featuring large coefficients at the meso positions as well (Fig. 5b). This orbital symmetry is certainly beneficial for the forward electron transfer $\left(k_{\mathrm{ET} 1}\right)$ via the bridging unit. After the internal redox reaction generating the gold(II) porphyrin, the spin density is located in the $5 d_{x 2-y 2}$ orbital of gold (with some spin delocalisation onto the coordinating nitrogen atoms), and hence in a $\sigma$-type orbital relative to the porphyrin planes (Fig. 5c). This will certainly retard the direct back-electron transfer to the $\mathrm{a}_{2 \mathrm{u}} \mathrm{SOMO}$ of the zinc porphyrin site. Back-electron transfer will consequently occur via the higher energy chargeshifted state ${ }^{3}\left[\mathrm{Zn}^{\prime \prime}\left(\mathrm{P}^{\bullet+}\right)-\mathrm{Au} u^{\prime \prime \prime}\left(\mathrm{P}^{\bullet-}\right)\right]^{+}$. This will contribute to the large lifetime of the charge-shifted state.

Reduction of the long-lived charge-shifted state ${ }^{3}\left[\mathrm{Zn}^{\prime \prime}\left(\mathrm{P}^{\bullet+}\right)\right.$ $\left.A u^{\prime \prime}(P)\right]^{+}$will give the neutral dyad $Z n^{\prime \prime}(P)-A u^{\prime \prime}(P)$ (Fig. 5d). The $Z n-$ $\mathrm{N}$ distances in $\mathrm{Zn}^{\prime \prime}(\mathrm{P})-\mathrm{Au}^{\prime \prime}(\mathrm{P})$ correspond to those of the initial ground state, yet the Au-N bond lengths and the spin-density still fit to a gold(II) description. The next section discusses electron transfer processes giving the neutral dyad $\mathrm{Zn}(\mathrm{P})-\mathrm{Au} \mathrm{u}^{\prime \prime}(\mathrm{P})$.

\section{Visible light-induced electron transfer processes.}

As the lifetimes of the visible light-induced charge-shifted states ${ }^{1,3}\left[\mathrm{Zn}^{\prime \prime}\left(\mathrm{P}^{\bullet+}\right)-\mathrm{Au}^{\prime \prime}(\mathrm{P})\right]^{+}\left(\tau=3.0-3.4 \mathrm{~ns}\right.$ for $\left.[1]^{+}-[3]^{+}\right)$are long enough to enable subsequent bimolecular reactions and the charge-shifted state is quite oxidising $\left(E_{1 / 2}\left(\mathrm{Zn}^{\prime \prime}\left(\mathrm{P}^{\bullet+}\right)\right)=0.42 \mathrm{~V}\right.$ and $0.49 \mathrm{~V}$ vs. ferrocene for [1] ${ }^{+}$and [3] ${ }^{+}$; Table 2$)$, the charge-shifted states were reductively quenched by $\mathrm{NEt}_{3}\left(E_{\mathrm{p}}=0.47 \mathrm{vs}\right.$. ferrocene in $\left.\mathrm{CH}_{3} \mathrm{CN}^{[31]}\right)$. The resulting neutral species $\mathrm{Zn}^{\prime \prime}(\mathrm{P})-\mathrm{Au}^{\prime \prime}(\mathrm{P})$ should display the characteristic spectroscopic features of a gold(II) complex. ${ }^{[13]}$ For comparison of the spectral data, $\mathrm{Zn}(\mathrm{P})-\mathrm{Au}^{\prime \prime}(\mathrm{P})$ was also prepared by chemical reduction of the cationic dyads with one equivalent of potassium graphite.

Gratifyingly, photochemical ( 10 eq NEt $3,420 \pm 5 \mathrm{~nm}$ ) and chemical reduction ( 1 eq $\mathrm{KC}_{8}$ ) yield species displaying the same electronic (Supporting Information, Fig. S22 - S23) and X-band EPR spectra (at $77 \mathrm{~K}$ ) (Supporting Information, Fig. S24). In addition, XANES spectra of [3][PF $]$ at the gold $\mathrm{L}_{3}$-edge confirm the formation of gold(II) in the presence of $\mathrm{NEt}_{3}$ under irradiation $(420 \pm 5 \mathrm{~nm})$ (Supporting Information, Fig. S25) with results fully analogous to the prototype Au"(TPP). ${ }^{[13]}$ Furthermore, dioxygen re-oxidises the neutral species $\mathrm{Zn}^{\prime \prime}(\mathrm{P})-A u^{\prime \prime}(\mathrm{P}) \mathbf{3}$ back to the starting material [3] ${ }^{+}$ according to XANES (Supporting Information, Fig. S25). The EXAFS region of the XANES remains essentially identical for the $A u^{\prime \prime}$ and $A u^{\prime l l}$ species suggesting full structural integrity of the $\left[\mathrm{AuN}_{4}\right]$ moiety during the redox processes (Supporting Information, Fig. S25). 
a)
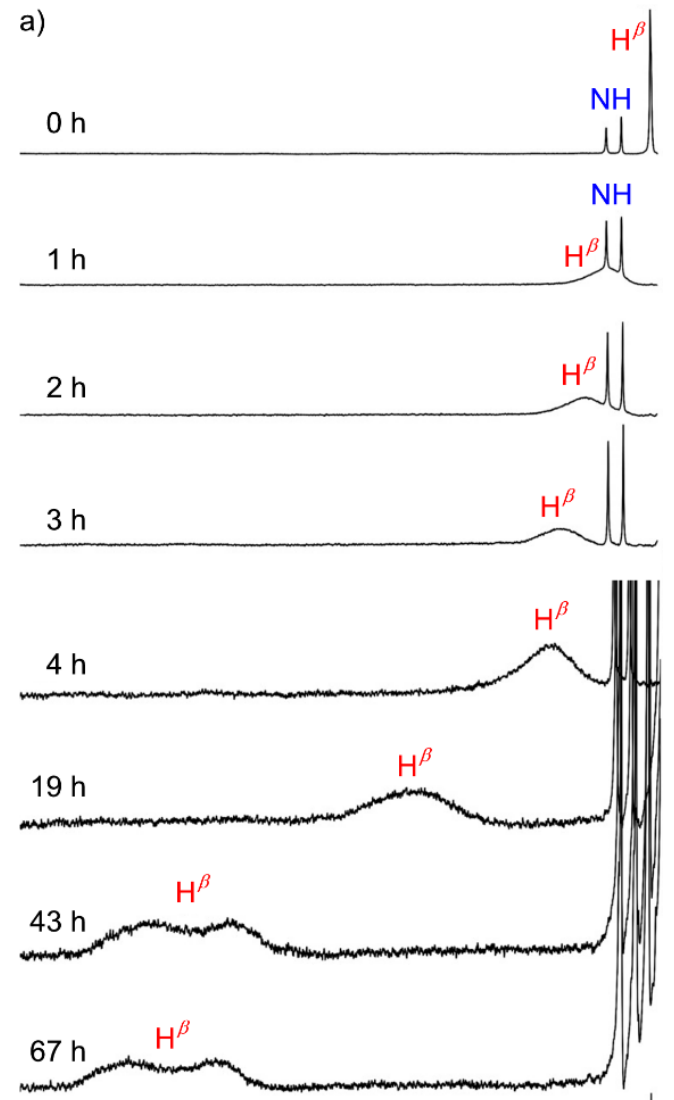

b)

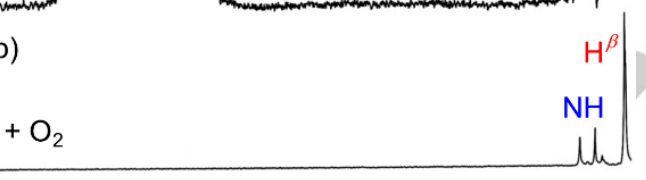

$\begin{array}{llllllllllll}32 & 30 & 28 & 26 & 24 & 22 & 20 & 18 & 16 & 14 & 12 & 10\end{array}$ $\delta / \mathrm{ppm}$

Figure 6. ${ }^{1} \mathrm{H}$ NMR spectra of $[3]\left[\mathrm{PF}_{6}\right]$ in the presence of 10 eq $\mathrm{NEt}_{3}$ under irradiation with $420 \pm 5 \mathrm{~nm}$ over time in $d_{7}-\mathrm{DMF}$ and b) ${ }^{1} \mathrm{H}$ NMR spectrum of the resulting solution after reaction with $\mathrm{O}_{2}$.

Similar to $\mathrm{Au}(\mathrm{TPP})^{[13 a]}$, the neutral dyads $\mathbf{1}$ and $\mathbf{3}$ display paramagnetically shifted ${ }^{1} \mathrm{H}$ NMR resonances ${ }^{[32]}$ for the gold(II) porphyrin subunit at room temperature. This is especially pronounced for the $\beta$ protons of the gold(II) porphyrin with $\delta=26$ - 33 ppm (Fig. 6, Supporting Information, Fig. S26). ${ }^{[13]}$ The Au ${ }^{1 / / I I I}$ self-exchange between gold porphyrins is rapid on the ${ }^{1} \mathrm{H}$ NMR timescale (fast exchange regime) yielding averaged resonances with the chemical shifts weighted with the Aull molar fraction. ${ }^{[13]}$ Consequently, ${ }^{1} \mathrm{H}$ NMR spectroscopy allows monitoring the visible-light induced reductive quenching of the dyads in the presence of $\mathrm{NEt}_{3}$ and the formation of the gold(II) species over time (Fig. 6). Although the reaction is rather slow, almost quantitative reduction of [3] ${ }^{+}$to 3 by NEt $_{3}$ is achieved in $67 \mathrm{~h}$ under irradiation at $420 \pm 5 \mathrm{~nm}$. The quite low reaction rate is probably due to the competition between valence isomerisation of ${ }^{1,3}\left[Z^{\prime \prime}\left(P^{\bullet+}\right)-A u^{\prime \prime \prime}\left(P^{\bullet-}\right)\right]^{+}$to the long-lived, productive ${ }^{1,3}\left[\mathrm{Zn}^{\prime \prime}\left(\mathrm{P}^{\bullet+}\right)-\right.$ $\left.A u^{\prime \prime}(P)\right]^{+}$state and the recombination of ${ }^{1,3}\left[\mathrm{Zn}^{\prime \prime}\left(\mathrm{P}^{\bullet+}\right)-\mathrm{Au}^{\mathrm{III}}\left(\mathrm{P}^{\bullet-}\right)\right]^{+}$to the ground state ( $k_{\mathrm{BET} 1}$; Fig. 3 , Table 3 ), so that only a fraction of the excited dyads is competent to react with amines. In addition, at increasing conversion to gold(II) the inner filter effect of the gold(II) product (Supporting Information, Fig. S26 - S27) captures most of the incident light further slowing down the reaction. Under the same conditions, [1] ${ }^{+}$is only converted to $~ 34 \%$ according to ${ }^{1} \mathrm{H}$ NMR monitoring (Supporting Information, Fig. S26 - S27). This might be due to the lower oxidation potential of [1] ${ }^{+}$(Table 2) and the very unfavourable bathochromic shift of the Soret band of the gold(II) unit ${ }^{[13 b, 33]}$ capturing more of the incident light as the reaction proceeds (Supporting Information, Fig. S23b).

We further confirmed, that both irradiation into the Soret $(420 \pm 5$ $\mathrm{nm})$ and the $Q$ band $(560 \pm 5 \mathrm{~nm})$ trigger the reduction by $\mathrm{NEt}_{3}$ (Supporting Information, Fig. S26) confirming our mechanistic picture, that IC from $S_{2}$ to $S_{1}$ precedes the electron transfer steps and that the $S_{1}$ state is competent to evolve to the charge-shifted states (Fig. 3). In the absence of $\mathrm{NEt}_{3}$, the dyads are photostable (Supporting Information, Figure S27b), substantiating the bimolecular electron transfer between the dyad and the amine. Vice versa, $\mathrm{NEt}_{3}$ is unable to reduce the dyads in the dark.

To the best of our knowledge, the possibility to monitor photoinduced electron transfer by conventional NMR spectroscopy is a very rare situation due to the paramagnetic nature of intermediates in one-electron transfer reactions, which often hampers observation of NMR resonances. ${ }^{[32]}$ Re-oxidation of the gold(II) species to the starting material by dioxygen is also successfully confirmed by ${ }^{1} \mathrm{H}$ NMR spectroscopy (Fig. 6). In the absence of $\mathrm{O}_{2}$ as oxidant, the neutral gold(II)-containing dyads should be able to reduce substrates with redox potentials above $-1.0 \mathrm{~V}$ (Table 2).

As an initial test reaction, we employed the reduction of aromatic azides to anilines. ${ }^{[34]}$ Azides are irreversibly reduced around potentials of $E_{\mathrm{p}}=-0.88 \vee$ to $-1.22 \mathrm{~V}$ vs. ferrocene. ${ }^{[35]}$ Hence, gold(II) should be competent to reduce azides (Table 2). In analogy to the procedure developed by Liu et al. using ${ }^{\mathrm{i}} \mathrm{Pr}_{2} \mathrm{NEt}$ as sacrificial reductant (10 eq; $E_{p}=0.34 \mathrm{~V}$ vs. ferrocene ${ }^{[36]}$ ), acetic acid as proton donor (10 eq), 4-azidobenzoic acid as substrate and $\left[\mathrm{Ru}(\mathrm{bpy})_{3}\right]^{2+}(5 \mathrm{~mol}-\%)$ as the classical photosensitizer (bpy = 2,2'-bipyridine), ${ }^{[37]}$ we employed the same conditions, yet replacing $\left[\mathrm{Ru}(\mathrm{bpy})_{3}\right]^{2+}$ by $[3]\left[\mathrm{PF}_{6}\right]$ (1 mol-\%). Gratifyingly, 4azidobenzoic acid is converted to 4 -aminobenzoic acid under these conditions after $72 \mathrm{~h}$ irradiation with $420 \mathrm{~nm}$ in $d_{7}$-DMF (Scheme 3; $50 \%$ unoptimised spectroscopic yield; Supporting Information, Fig. S28). 


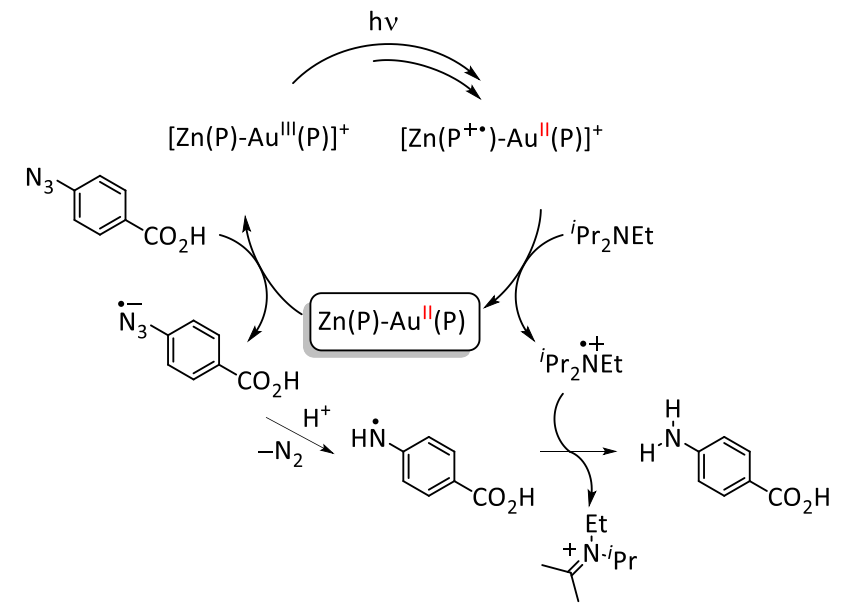

Scheme 3. Proposed mechanism of the $\left[\mathrm{Zn}(\mathrm{P}) A u^{\prime \prime \prime}(P)\right]^{+}$-mediated azidereduction induced by visible light $\left(420 \pm 5 \mathrm{~nm}, d_{7}-\mathrm{DMF}\right)$.

Scheme 3 illustrates the proposed mechanism including the mechanistic results from the previous sections. The sensitizer $\left[\mathrm{Zn}(\mathrm{P})-\mathrm{Au} \mathrm{u}^{\mathrm{III}}(\mathrm{P})\right]^{+}$is excited by visible light $(420 \pm 5 \mathrm{~nm})$ to initially yield $S_{2}$ state(s). A fraction evolves to the long-lived ${ }^{1,3} \mathrm{CSh}$ states with gold(II) centres. These long-lived CSh state are reduced by the amine generating the neutral $\mathrm{Zn}(\mathrm{P})-A u^{\prime \prime}(\mathrm{P})$ species and the amine radical cation. The gold(II) complex $\mathrm{Zn}(\mathrm{P})-\mathrm{Au}^{\prime \prime}(\mathrm{P})$ is oxidised by the azide re-generating $\left[\mathrm{Zn}(\mathrm{P})-\mathrm{Au}^{\prime \prime \prime}(\mathrm{P})\right]^{+}$. The azide radical anion finally eliminates dinitrogen, adds a proton (from acetic acid) and a hydrogen atom (from the amine radical cation) furnishing the aniline as suggested in the literature. ${ }^{[35]}$

\section{Conclusions}

In summary, $\left[\mathrm{Zn} n(\mathrm{P})-\mathrm{Au}{ }^{\prime \prime \prime}(\mathrm{P})\right]^{+}$dyads [1][PF 6$]-[3]\left[\mathrm{PF}_{6}\right]$ undergo ultrafast photoinduced electron transfer. A fraction of these excited states decays to a long-lived charge-shifted state ${ }^{1,3}\left[\mathrm{Zn}^{\prime \prime}\left(\mathrm{P}^{\bullet+}\right)-\mathrm{Au}^{\prime \prime}(\mathrm{P})\right]^{+}$(lifetime $\sim 3 \mathrm{~ns}$ ) The redox potentials of zinc(II) porphyrins and gold(III) porphyrins place the respective charge-shifted states $1.25 \mathrm{eV}-1.48 \mathrm{eV}$ relative to the ground state and well below the individual singlet and triplet excited states of the zinc and gold porphyrins $\left(S_{1}(Z n), S_{1}(A u), T_{1}(Z n), T_{1}(A u)\right)$. Consequently, the charge-shifted states can be populated from the local $S_{1}(M)$ and $T_{1}(M)$ states via an intermediate chargeshifted state ${ }^{1,3}\left[\mathrm{Zn}^{\prime \prime}\left(\mathrm{P}^{\bullet+}\right)-\mathrm{Au}^{\text {III }}\left(\mathrm{P}^{\bullet-}\right)\right]^{+}$with $\pi$ radical character at the gold site. After valence isomerisation to the long-lived chargeshifted states ${ }^{1,3}\left[\mathrm{Zn}^{\prime \prime}\left(\mathrm{P}^{\bullet+}\right)-\mathrm{A} u^{\prime \prime}(\mathrm{P})\right]^{+}$with metal radical character at the gold site, bimolecular reduction of the $\mathrm{Zn}^{\prime \prime}\left(\mathrm{P}^{\bullet+}\right)$ site with amines yields a stable gold(II) species $\mathrm{Zn}(\mathrm{P})-\mathrm{Au}^{\prime \prime}(\mathrm{P})$ as confirmed by UV/Vis, EPR, XANES and NMR spectroscopy. This gold(II) dyad $\mathrm{Zn}(\mathrm{P})-\mathrm{Au}{ }^{\prime \prime}(\mathrm{P})$ reduces aromatic azides regenerating the initial gold(III) dyad [Zn" $\left.(P)-A u^{\prime \prime \prime}(P)\right]^{+}$and hence closing a catalytic cycle. This study identifies the most important light-induced steps and key intermediates of dyads containing gold(III) porphyrins as electron acceptors after excitation with visible light. Furthermore, this study delivers the first UV/Vis, EPR, XANES and NMR spectroscopic evidences for the involvement of tetracoordinate gold(II) species during photoredox catalysis. ${ }^{[8,9,10,12,13]}$ This also paves the way for further studies of photoinduced gold-catalysed reactions with low-coordinate gold(II) species proposed as transient intermediates. ${ }^{[16]}$

\section{Author contributions}

S.P. prepared and characterised the compounds (NMR, UV/Vis, EPR, MS, CV) and performed the PET experiments and DFT calculations. A.P. and S.L. performed and analysed the timeresolved photoluminescence and transient absorption spectroscopy experiments. L.B. and M.B. performed and analysed the XANES experiments. L.G. and T.O. contributed to the PET experiments and the catalytic test reactions. K.H. designed the experiments and supervised the project.

\section{Acknowledgements}

Financial support from the Center for INnovative and Emerging MAterials (CINEMA), the Forschungsinitiative Rheinland-Pfalz (LESSING) and the Deutsche Forschungsgemeinschaft [DFG, Priority Program SPP 2102 "Light-controlled reactivity of metal complexes" (LO 714/11-1)] is gratefully acknowledged. Parts of this research were conducted using the supercomputer Mogon and advisory services offered by Johannes Gutenberg University Mainz (www.hpc.uni-mainz.de), which is a member of the AHRP and the Gauss Alliance e.V.. PETRA III is acknowledged for provision of beamtime, Dr. Aleksandr Kalinko for help during XANES measurements.

\section{References}

[1] a) M. Natali, S. Campagna, F. Scandola, Chem. Soc. Rev. 2014, 43 4005-4018; b) R. A. Marcus, N. Sutin, Biochim. Biophys. Acta 1985, 811, 265-322.

[2] a) B. O'Regan, M. Grätzel, Nature 1991, 353, 737-740; b) D. Gust, T. A Moore, A L. Moore, Acc. Chem. Res. 1993, 26, 198-205; c) L. Peter, Acc. Chem. Res. 2009, 42, 1839-1847; d) A. Magnuson, M. Anderlund, O. Johansson, P. Lindblad, R. Lomoth, T. Polivka, S. Ott, K. Stensjö, S. Styring, V. Sundström, L. Hammarström, Acc. Chem. Res. 2009, 42, 1899-1909; e) T. Cardona, A. Sedoud, N. Cox, A. W. Rutherford, Biochim. Biophys. Acta 2012, 1817, 26-43; f) J. Deisenhofer, O. Epp, K. Miki, R. Huber, H. Michel, Nature 1985, 318, 618-624; g) S. Niwa, L. J. Yu, K. Takeda, Y. Hirano, T. Kawakami, Z. Y. Wang-Otomo, K. Miki, Nature 2014, 508, 228-232.

[3] B. Albinsson, J. Mårtensson, J. Photochem. Photobiol. C 2008, 9, 138155.

[4] a) H. Imahori, D. M. Guldi, K. Tamaki, Y. Yoshida, C. Luo, Y. Sakata, S Fukuzumi, J. Am. Chem. Soc. 2001, 123, 6617-6628; b) H. Imahori, K Tamaki, Y. Araki, Y. Sekiguchi, O. Ito, Y. Sakata, S. Fukuzumi, J. Am. Chem. Soc. 2002, 124, 5165-5174; c) S. Fukuzumi, K. Okamoto, H. Imahori, Angew. Chem. 2002, 114, 642-644; Angew. Chem. Int. Ed. 2002, 41, 620-622; d) H. Imahori, Y. Sekiguchi, Y. Kashiwagi, T. Sato Y. Araki, O. Ito, H. Yamada, S. Fukuzumi, Chem. Eur. J. 2004, 10, 3184 3196; e) M. U. Winters, E. Dahlstedt, H. E. Blades, C. J. Wilson, M. J. Frampton, H. L. Anderson, B. Albinsson, J. Am. Chem. Soc. 2007, 129 4291-4297; f) C. A. Wijesinghe, M. E. El-Khouly, M. E. Zandler, S. Fukuzumi, F. D‘Souza, Chem. Eur. J. 2013, 19, 9629-9638; g) J. Melomedov, J. R. Ochsmann, M. Meister, F. Laquai, K. Heinze, Eur. J. Inorg. Chem. 2014, 1984-2001; h) S. Fukuzumi, K. Okamoto, Y. Yoshida, H. Imahori, Y. Araki, O. Ito, J. Am. Chem. Soc. 2003, 125, 1007-1013. 
[5] a) S. L. Gould, G. Kodis, R. E. Palacios, L. de La Garza, A. Brune, D. Gust, T. A. Moore, A. L. Moore, J. Phys. Chem. B 2004, 108, 10566 10580 ; b) D. Gust, T. A. Moore, A. L. Moore, A. N. Macpherson, A. Lopez, J. M. DeGraziano, I. Gouni, E. Bittersmann, G. R. Seely, F. Gao, R. A Nieman, X. C. Ma, L. J. Demanche, S.-C. Hung, D. K. Luttrull, S.-J. Lee, P. K. Kerrigan, J. Am. Chem. Soc. 1993, 115, 11141-11152.

[6] a) D. Gust, T. A. Moore, A. L. Moore, L. Leggett, S. Lin, J. M. DeGraziano, R. M. Hermant, D. Nicodem, P. Craig, G. R. Seely, R. A. Nieman, J. Phys. Chem. 1993, 97, 7926-7931; b) S. K. Das, B. Song, A. Mahler, V. N. Nesterov, A. K. Wilson, O. Ito, F. D'Souza, J. Phys. Chem. C 2014 118, 3994-4006; c) T. H. Ngo, D. Zieba, W. A. Webre, G. N. Lim, P. A Karr, S. Kord, S. Jin, K. Ariga, M. Galli, S. Goldup, J. P. Hill, F. D'Souza, Chem. Eur. J. 2016, 22, 1301-1312.

[7] M. Lauck, C. Förster, D. Gehrig, K. Heinze, J. Organomet. Chem. 2017, $847,33-40$.

[8] a) I. M. Dixon, J.-P. Collin, J.-P. Sauvage, F. Barigelletti, L. Flamigni, Angew. Chem. 2000, 112, 1348-1351; Angew. Chem. Int. Ed. 2000, 39 1292-1295; b) D. B. Amabilino, J.-P. Sauvage, New. J. Chem. 1998, 22 395-409; c) V. Heitz, S. Chardon-Noblat, J.-P. Sauvage, Tetrahedron Lett. 1991, 32, 197-198; d) A. Harriman, F. Odobel, J.-P. Sauvage, J. Am. Chem. Soc. 1995, 117, 9461-9472; e) A. M. Brun, A. Harriman, V. Heitz, J. P. Sauvage, J. Am. Chem. Soc. 1991, 113, 8657-8663.

[9] a) E. K. L. Yeow, P. J. Sintic, N. M. Cabral, J. N. H. Reek, M. J. Crossley, K. P. Ghiggino, Phys. Chem. Chem. Phys. 2000, 2, 4281-4291; b) K. Ohkubo, P. J. Sintic, N. V. Tkachenko, H. Lemmetyinen, E. Wenbo, Z Ou, J. Shao, K. M. Kadish, M. J. Crossley, S. Fukuzumi, Chem. Phys. 2006, 326, 3-14; c) K. Ohkubo, R. Garcia, P. J. Sintic, T. Khoury, M. J. Crossley, K. M. Kadish, S. Fukuzumi, Chem. Eur. J. 2009, 15, 1049310503; d) M. E. El-Khouly, S. Fukuzumi, Photochem. Photobiol. 2016 15, 1340-1346; e) S. Fukuzumi, K. Ohkubo, E. Wenbo, Z. Ou, J. Shao, K. M. Kadish, J. A. Hutchison, K. P. Ghiggino, P. J. Sintic, M. J. Crossley, J. Am. Chem. Soc. 2003, 125, 14984-14985.

[10] a) J. Fortage, A. Scarpaci, L. Viau, Y. Pellegrin, E. Blart, M. Falkenström, L. Hammarström, I. Asselberghs, R. Kellens, W. Libaers, K. Clays, M. P Eng, F. Odobel, Chem. Eur. J. 2009, 15, 9058-9067; b) J. Fortage, J. Boixel, E. Blart, H. C. Becker, F. Odobel, Inorg. Chem. 2009, 48, 518526; c) J. Fortage, J. Boixel, E. Blart, L. Hammarström, H. C. Becker, F Odobel, Chem. Eur. J. 2008, 14, 3467-3480; d) E. Göransson, J. Boixel, J. Fortage, D. Jacquemin, H.-C. Becker, E. Blart, L. Hammarström, F. Odobel, Inorg. Chem. 2012, 51, 11500-11512.

[11] a) D. Huang, X. Zhang, E. J. L. McInnes, J. McMaster, A. J. Blake, E. S. Davies, J. Wolowska, C. Wilson, M. Schröder, Inorg. Chem. 2008, 47 9919-9929; b) S. Seidel, K. Seppelt, Science 2000, 290, 117-118.

[12] a) Z. Ou, K. M. Kadish, W. E. J. Shao, P. J. Sintic, K. Ohkubo, S. Fukuzumi, M. J. Crossley, Inorg. Chem. 2004, 43, 2078-2086; b) K. M. Kadish, W. E, Z. Ou, J. Shao, P. J. Sintic, K. Ohkubo, S. Fukuzumi, M. J. Crossley, Chem. Commun. 2002, 356-357.

[13] a) S. Preiß, C. Förster, S. Otto, M. Bauer, P. Müller, D. Hinderberger, H. Hashemi Haeri, L. Carella, K. Heinze, Nat. Chem. 2017, 9, 1249-1255 b) S. Preiß, J. Melomedov, A. Wünsche von Leupoldt, K. Heinze, Chem. Sci. 2016, 7, 596-610; c) K. Heinze, Angew. Chem. 2017, 129, 16342 16350; Angew. Chem. Int. Ed. 2017, 56, 16126-16134.

[14] a) D. Pflästerer, A. S. K. Hashmi, Chem. Soc. Rev. 2016, 45, 13311367; b) A. M. Asiri, A. S. K. Hashmi, Chem. Soc. Rev. 2016, 45, 44714503; c) R. Dorel, A. M. Echavarren, Chem. Rev. 2015, 115, 9028-9072.

[15] C.-Y. Zhou, P. W. H.Chan, C.-M. Che, Org. Lett. 2006, 8, 325-328.

[16] a) B. Sahoo, M. N. Hopkinson, F. Glorius, J. Am. Chem. Soc. 2013, 135, 5505-5508; b) M. N. Hopkinson, A. Tlahuext-Aca, F. Glorius, Acc. Chem Res. 2016, 49, 2261-2272; c) J. Xie, S. Shi, T. Zhang, N. Mehrkens, M. Rudolph, A. S. K. Hashmi, Angew. Chem. Int. Ed. 2015, 54, 6046-6050; Angew. Chem. 2015, 127, 6144-6148; d) J. Xie, J. Yu, M. Rudolph, F. Rominger, A. S. K. Hashmi, Angew. Chem. Int. Ed. 2016, 55, 94169421; Angew. Chem. 2016, 128, 9563-9568; e) J. Xie, J. Li, V Weingand, M. Rudolph, A. S. K. Hashmi, Chem. Eur. J. 2016, 22 12646-12650; f) L. Huang, M. Rudolph, F. Rominger, A. S. K. Hashmi, Angew. Chem. 2016, 128, 4888-4893; Angew. Chem. Int. Ed. 2016, 55 4808-4813; g) S. Witzel, J. Xie, M. Rudolph, A. S. K. Hashmi, Adv. Synth. Catal. 2017, 359, 1522-1528; h) S. Witzel, K. Sekine, M. Rudolph, A. S.
K. Hashmi, Chem. Commun. 2018, 54, 13802-13804; i) M. S. Winston, W. J.Wolf, F. D. Toste, J. Am Chem Soc. 2014, 136, 7777-7782; j) X Z. Shu, M. Zhang, Y. He, H. Frei, F. D. Toste, J. Am. Chem. Soc. 2014 136, 5844-5847; k) S. Kim, J. Rojas-Martin, F. D. Toste, Chem. Sci. 2016, 7, 85-88.

[17] a) J. Melomedov, J. R. Ochsmann, M. Meister, F. Laquai, K. Heinze, Eur. J. Inorg. Chem. 2014, 2902-2915; b) M. O. Senge, Chem. Commun. 2011, 47, 1943-1960; c) J. S. Lindsey, Acc. Chem. Res. 2010, 43, 300 311; d) K. Heinze, A. Reinhart, Dalton Trans. 2008, 469-480.

[18] E. B. Fleischer, A. Laszlo, Inorg. Nucl. Chem. Lett. 1969, 5, 373-376.

[19] J. Melomedov, A. Wünsche von Leupoldt, M. Meister, F. Laquai, K. Heinze, Dalton Trans. 2013, 42, 9727-9739.

[20] a) A. Antipas, J. W. Buchler, M. Gouterman, P. D. Smith, J. Am. Chem Soc. 1978, 100, 3015-3024; b) A. Antipas, D. Dolphin, M. Gouterman, E. C. Johnson, J. Am. Chem. Soc. 1978, 100, 7705-7709.

[21] a) V. W.-W. Yam, E. C.-C. Cheng, Top. Curr. Chem. 2007, 281, 269 309; b) M. P. Eng, T. Ljungdahl, J. Andréasson, J. Mårtensson, B. Albinsson, J. Phys. Chem. A 2005, 109, 1776-1784.

[22] J. Heinze, Angew. Chem. 1984, 96, 823-840; Angew. Chem. Int. Ed. 1984, 23, 831-847.

[23] a) D. Rehm, A. Weller, Isr. J. Chem. 1970, 8, 259-271; b) A. Weller, $Z$. Phys. Chem. 1982, 133, 93-98.

[24] a) R. A. Marcus, J. Chem. Phys. 1956, 24, 966-978; b) R. A. Marcus, Annu. Rev. Phys. Chem. 1964, 15, 155-196; c) R. A. Marcus, Angew. Chem. 1993, 105, 1161-1172; Angew. Chem. Int. Ed. 1993, 32, 11111121

[25] J. Andréasson, G. Kodis, S. Lin, A. L. Moore, T. A. Moore, D. Gust, J. Mårtensson, B. Albinsson, Photochem. Photobiol. 2002, 76, 47-50.

[26] N. J. Turro, Modern Molecular Photochemistry, University Science Books, 1991.

[27] a) G. N. Lim, C. O. Obondi, F. D'Souza, Angew. Chem. 2016, 128 11689-11693; Angew. Chem. Int. Ed. 2016, 55, 11517-11521; b) V. A Walters, J. C. de Paula, B. Jackson, C. Nutaitis, K. Hall, J. Lind, K. Cardozo, K. Chandran, D. Raible, C. M. Phillips, J. Phys. Chem. 1995 99, 1166-1171.

[28] R. L. Brookfield, H. Ellul, A. Harriman, J. Chem. Soc., Faraday Trans. 1985, 81, 1837-1848

[29] P. K. Poddutoori, G. N. Lim, S. Vassiliev, F. D'Souza, Phys. Chem Chem. Phys. 2015, 17, 26346-26358.

[30] Y. Kobayashi, T. Katayama, T. Yamane, K. Setoura, S. Ito, H. Miyasaka J. Abe, J. Am. Chem. Soc. 2016, 138, 5930-5938.

[31] N. G. Connelly, W. E. Geiger, Chem. Rev. 1996, 96, 877-910.

[32] Solution NMR of Paramagnetic Molecules (Eds. I. Bertini, C. Luchinat, G. Parigi), Curr. Methods Inorg. Chem. 2001, vol. 2, Elsevier.

[33] Z. Ou, W. Zhu, Y. Fang, P. J. Sintic, T. Khoury, M. J. Crossley, K. M. Kadish, Inorg. Chem. 2011, 50, 12802-12809.

[34] E. F. V. Scriven, K. Turnbull, Chem. Rev. 1988, 88, 298-368.

[35] a) D. E. Herbranson, M. D. Hawley, J. Org. Chem. 1990, 55, 4297-4303; b) J. Moutet, A. Ourari, A. Zouaoui, Electrochim. Acta 1992, 37, 12611263 ; c) M. Warrier, M. K. F. Lo, H. Monbouquette, M. A. Garcia-Garibay, Photochem. Photobiol. Sci. 2004, 3, 859-862.

[36] G. J. Barbante, N. Kebede, C. M. Hindson, E. H. Doeven, E. M. Zammit, G. R. Hanson, C. F. Hogan, P. S. Francis, Chem. Eur. J. 2014, 20 , 14026-14031.

[37] Y. Chen, A. S. Kamlet, J. B. Steinman, D. R. Liu, Nat. Chem. 2011, 3, 146-153.

Keywords: electron transfer • gold • paramagnetic NMR spectroscopy $\bullet$ photoinduced electron transfer • porphyrins 
WILEY-VCH

\section{FULL PAPER}

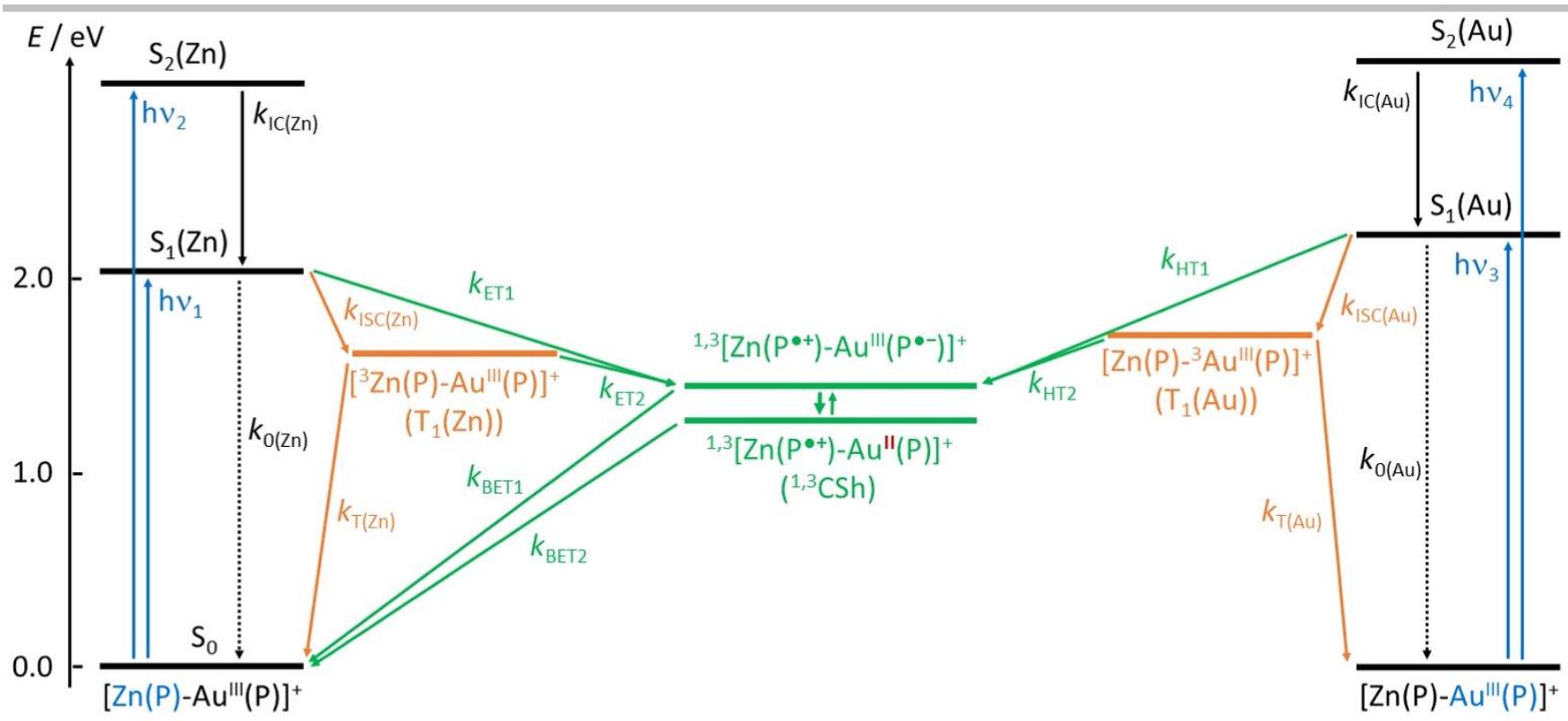

Figure 3. 
Entry for the Table of Contents (Please choose one layout)

Photoinduced Electron Transfer

\section{FULL PAPER}

Long-lived gold(II) intermediates form after light irradiation of zinc(II)porphyrin-gold(III)-porphyrin dyads. These gold(II) intermediates are unambiguously confirmed by various spectroscopic techniques and they are competent in sequential redox processes.

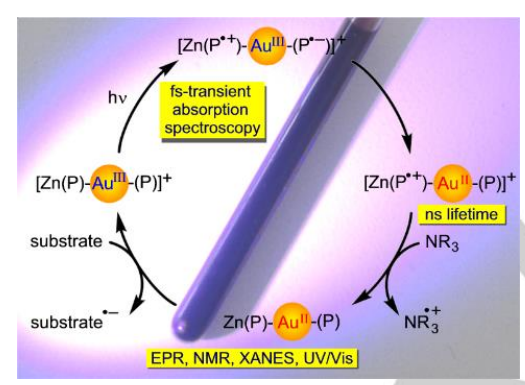

S. Preiß, A. Päpcke, L. Burkhardt, L. Großmann, S. Lochbrunner, M. Bauer, T. Opatz, K. Heinze*

Page No. - Page No.

Gold(II) Porphyrins in Photoinduced Electron Transfer Reactions 